\title{
LOS ORÍGENES DE LA CIVILIZACIÓN EN EL PERÚ: EL ÁREA NORCENTRAL. Y EL VALLE DE SUPE DURANTE EL ARCAICO TARDÍO
}

Rutb Shady S.

Camilo Dolorier $T$.

Fanny Montesinos

Lyda Casas $S$.

\section{Resumen}

En este trabajo presentamos los principales centros urbanos identificados en le valle de Supe, en base al reconocimiento realizado por los autores entre los años 1994 y 1995. Se adelantan algunas inferencias que deben ser consideradas todavía como preliminares en tanto no se realicen excavaciones en otros sitios del valle fuera de Caral, establecimientos donde se vienen realizando excavaciones desde 1996 y en base a las cuales se ha confrontado esta información.

Se plantea en este artículo, que durante el período Arcaico Tardío, existió en el valle de Supe un conjunto de centros urbanos, construido por una población que se hallaba culturalmente integrada, en el cual se habría formado el Estado prístino, con un gobierno unificado.

\section{Abstract}

In this work the authors present the main urban centers identified in the Supe valley, based on the survey made by them among the years 1994 and 1995. They anticipate some inferences that should still be considered as preliminary as long as excavations are not carried out in other sites of the valley outside of Caral, establishment where it is carrying out excavations from 1996 and based on which this information has been confronted.

In this article the authors state that during the Late Archaic period, it existed in the Supe valley a group of urban centers, built by a population that was culturally integrated, in which would have been formed the pristine State, with an unified government. 


\section{INTRODUCCIóN}

\begin{abstract}
"(..) que muriendo el uno curaca de un valle si el g(ue) le zuzedia era de su pachaca eredava tada la azienda tierras e ropa (...) y y este que eredava no era de su parzialidad no eredava $m(a) s$ del señorio y esta orden se tenia y guardava en los demas curacas de pachacas.. *
\end{abstract}

$\mathbf{L}$ a dinámica cultural generada en el área norcentral del Perú durante el Arcaico Tardío habría sido clave para el surgimiento de la civilización en el Perú, unos mil quinientos años antes de lo supuesto para Chavín de Huántar o unos quinientos años antes que en otras sociedades de la costa central y norte.

Se ha constatado que hasta la fecha, el valle de Supe en la costa norcentral del Perú presenta el mayor número de sitios arqueológicos con arquitectura monumental, perteneciente al período Arcaico Tardío, en un nivel precerámico. Los fechados radiocarbónicos obtenidos en la ciudad de Caral, uno de los centros urbanos más destacados, ubicado al inicio del valle medio, se ordenan entre 2600 y $2100 \mathrm{cal}$ a.C.

En este trabajo presentamos los principales centros urbanos identificados en el valle, en base al reconocimiento realizado entre los años 1994 y 1995 con los arqueólogos Fanny Montesinos, Lyda Casas y Camilo Dolorier. Adelantamos algunas inferencias que, en parte, deben ser consideradas todavía como preliminares, en tanto no se realicen excavaciones en otros sitios del valle fuera de Caral, establecimiento donde venimos excavando desde 1996 y en base al cual hemos confrontado aquella información.

Estamos planteando la existencia en el valle de Supe, durante el Arcaico Tardío, de un conjunto de centros urbanos, construido por una población, que se hallaba integrada culturalmente $y$ en la cual se habría formado el Estado prístino, con un gobierno unificado.

(") CASTRO, Cristóbal de y Diego de ORTEGa y MOREJON Relación de Chincha. Biblioteca Peruana. Primers Serie. Tomo III. Lima: Editores Técnicos Asociados, 1968 [1558] 486.
Por los rasgos que presentan los establecimientos de Supe, se puede señalar que en esa población se produjo durante el Arcaico Tardío el proceso más temprano de complejización social; y a esa experiencia sociocultural habrán de remitirse los investigadores interesados en el conocimiento de la organización de las estructuras sociopolíticas básicas en los Andes Centrales, pues allí se encuentran las formas originarias de su formación.

\section{EL ÁREA NORCENTRAL: CONTEXTO NATURAL Y CONDICIONES PARA LA ORGANIZACIÓN DE SOCIEDADES COMPLEJAS}

El área norcentral del Perú comprende un espacio geográfico muy contrastado y diverso. Se ubica al norte del departamento de Lima y se define del modo siguiente: al oeste por el Océano Pacífico y las estribaciones andinas, que comprende la región costeña entre los valles de Chancay y Santa; en el centro, por las sierras de los valles que forman los ríos costeños de esa área, que vierten sus aguas al Pacífico; entre los que destaca el Callejón de Huaylas, de suelos quebrados y diferenciados altitudinalmente, como corresponde a la cordillera andina; $y$ al oriente, por los valles cuyos ríos fluyen hacia la cuenca amazónica, como el Huallaga y Marañón.

El área presenta marcadas diferencias en el relieve, clima y recursos, no sólo entre las grandes regiones mencionadas sino también en el interior de cada una de ellas. Estas condiciones naturales, si bien en una etapa previa hicieron necesario un proceso casi singular de tratamiento de cada zona para la producción, una vez lograda ésta, la variabilidad productiva se habría convertido en un recurso atractivo para los pobladores del área.

Favorece la interacción en esta área la existencia de vías naturales de tránsito en el eje oesteEste, que interrelacionan las diversas zonas a más 
corta distancia que en otras partes del país. Estas vías han sido usadas como rutas de comunicación a través de los tiempos. Cabe destacar, sin embargo, algunas zonas propicias para los contactos:

1) La meseta andina, que presenta en las alturas un territorio casi plano y continuo con nevados y lagunas, que dan nacimiento a los ríos que fluyen tanto por la vertiente occidental para desembocar en el Océano Pacífico, como por la vertiente oriental contribuyendo a la gran cuenca del Amazonas. Espacio elevado que permite una articulación entre los diferentes valles al bajar desde sus nacientes.

2) El mar, hacia el occidente, que, asimismo, enlaza a las caletas y puertos a lo largo de la costa.

3) Algunos ríos de la cuenca amazónica, al oriente, como el Huallaga, que los pobladores han usado para relacionarse con otros ocupantes de los Andes y la Amazonía.

Es interesante observar que, dentro de aquella área, el valle de Supe ocupa una posición estratégica para la comunicación, con una serie de vías de tránsito que permite un rápido y fácil acceso a las sierras del Callejón de Huaylas, Conchucos y a los valles del Marañón y Huallaga, en la cuenca amazónica. Es decir, en menos tiempo y sin mayores dificultades, sus habitantes pueden hacer llegar a la costa productos de la sierra o la selva y viceversa. La vía de Supe ha sido utilizada tradicionalmente y hasta el presente para conectar regiones de costa, sierra o selva del país y tener acceso a una producción variada.

\section{CULTURAS DEL ÁREA NORCENTRAL DURANTE EL ARCAICO TARDÍO}

Han sido las condiciones diversas del medio natural y las adaptaciones culturales distintivas, resultantes del proceso de neolitización en el área norcentral, las que fomentaron el temprano interés de las sociedades por la comunicación y el intercambio, una vez que lograron desarrollar sus fuerzas productivas. De este modo, las poblaciones del área pudieron tener acceso a los productos provenientes de diferentes procesos adaptativos. Se puede señalar para entonces los avances agrícolas de las poblaciones asentadas en zonas del Santa y sus tributarios, con una serie de plantas domesticadas desde los 8000 años a.C., según indican los hallazgos en la cueva del Guitarrero (Lynch, 1980); además del conocimiento sobre la construcción de terrazas de cultivo y canales de riego, según la evidencia presentada para La Galgada (Grieder et al., 1988). Paralelamente, destacaba la experiencia ganada por las poblaciones costeńas en la tecnología pesquera, para la extracción masiva, la conservación de peces, moluscos y la comercialización de éstos, como indican los resultados obtenidos en los establecimientos de La Paloma (Quilter, 1989), Bandurria (Fung, 1988) y Huaca Prieta (Bird et al. 1985).
Foto 1. Vista panordmica del sitio arqueologico de Aspero.

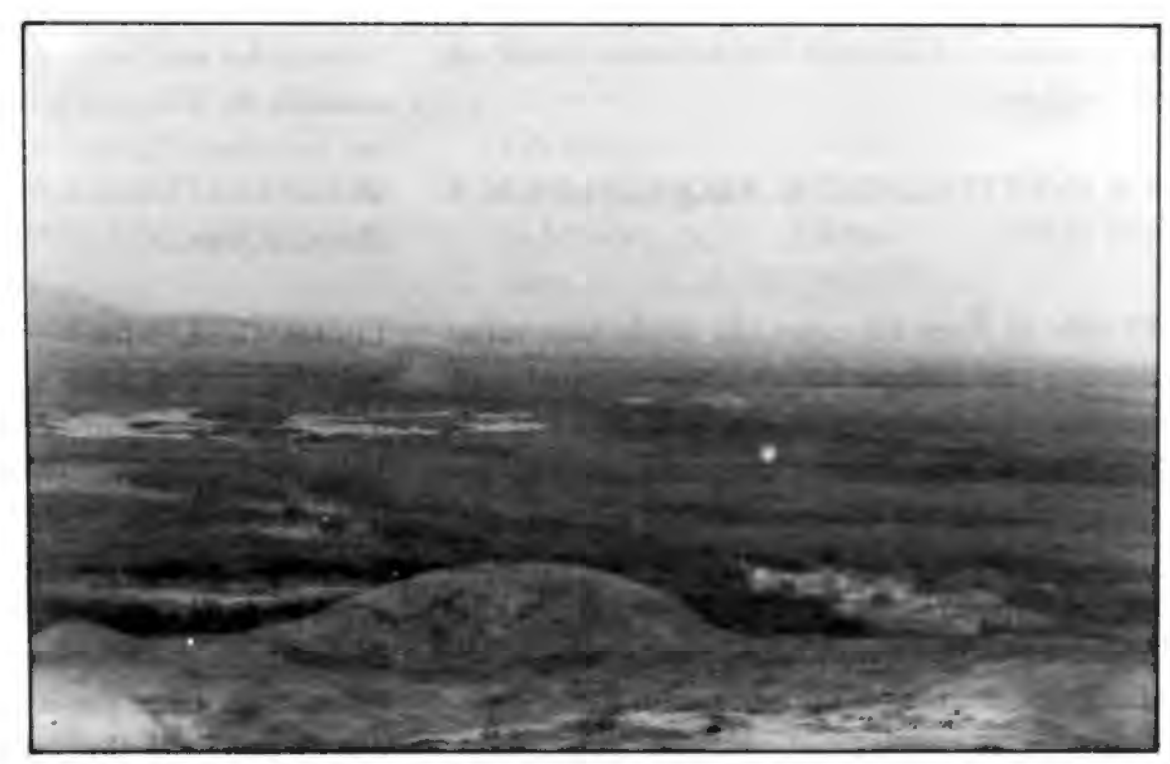


A través de procesos diferentes, entre los 3000 y 2000 años a.C., en las diversas regiones del área norcentral se encontraban sociedades con culturas singulares que vivían en centros urbanos, en torno a estructuras arquitectónicas de carácter cívico; habían alcanzado un cierto excedente productivo; un nivel de complejidad en su organización social y tenían acceso a bienes producidos en otras zonas, regiones y áreas. Así, productos marinos fueron consumidos en Huaricoto (Callejón de Huaylas) y Kotosh (Huánuco) o se trasladaron a establecimientos del litoral productos del oriente, como madera chonta a Bandurria (Huaura) o semillas de huayruro, achiote $y$ un caracol terrestre, megalobulimus, a Caral. No existe otra área en el país que muestre similar dinámica cultural en cuanto a desarrollo y relación entre regiones mediante la participación de sus poblaciones en una esfera de interacción a larga distancia durante el Arcaico Tardío.

Pero, si bien en las varias regiones del área norcentral habían culturas peculiares, todas ellas compartían una misma utradiciónn, como resultado de la interacción sostenida. Esta tradición, denominada "Kotosh" (Burger y Burger, 1980, 1985), está constituida por creencias, ritos y algunos símbolos, que formaron parte de la ideología asumida por el Estado de Supe.

Un conjunto de establecimientos, identificados en las diferentes regiones del área, correspondientes a las diversas culturas allí desarrolladas muestran evidencias de una activa participación en las esferas de interacción configuradas en el área durante el Arcaico Tardío (véase Shady, en este volumen).

\section{LA INVESTIGACIÓN ARQUEOLÓGICA EN SUPE}

El valle de Supe era conocido desde hace varias décadas por albergar a numerosos complejos arquitectónicos monumentales. Debido a esta impresionante obra humana, algunos investigadores asumieron que ella pertenecía a centros ceremoniales del período Formativo o a los períodos siguientes a éste. Ninguno de los estudiosos emprendió trabajos sistemáticos para recuperar los datos que permitieran la evaluación de tal suposición.
De los establecimientos del valle mencionados en la literatura arqueológica (Williams y Merino, 1979) sólo había sido excavado el sitio de Áspero (Feldman, 1980), ubicado en el litoral; $y$, a pesar que los resultados obtenidos suscitaron polémicas hipótesis en torno al sustento económico del desarrollo social complejo, no se asoció éste a los otros establecimientos del interior del valle. Mientras unos enfatizaron el rol del recurso marino como base del desarrollo civilizatorio; otros señalaron la importancia de la agricultura, como en otras partes del mundo. Sólo una investigadora, sobre la base de sondeos tubulares, realizados en unos sitios del valle de Supe, sugirió diferencias estacionales en la disponibilidad de alimentos y que la distinción en cuanto a recursos naturales entre las ecozonas del valle condujo a un patrón de subsistencia complejo, basado en la explotación de un conjunto diverso de recursos. Destacó la importancia del recurso terrestre, de plantas como guava, ají, erythrina, algarrobo, además de los recursos de monte, a los que se adicionaron algodón, maní, frijol y lúcuma. Ella señaló también el rol que habría tenido en la economía el aprovechamiento y probable intercambio de las algas marinas y que los recursos del mar tuvieron fuerte demanda de parte de la población asentada en el interior del valle, sobre todo en la época de estío (Zechenter, 1988: 330).

A partir de 1994 y durante dos ańos, un equipo de arqueólogos hicimos el reconocimiento a pie de cada margen del valle de Supe, entre el litoral y Peńico, en el valle medio superior. Desde este sitio hacia arriba del valle sólo visitamos determinados establecimientos, que aparecían en el catastro de Williams y Merino, asociados a plazas circulares. El espacio reconocido, donde se ubicaron los 18 establecimientos del Arcaico Tardío, comprende:

Litoral: 1859,75 ha. Valle bajo: 9214,5 ha.

Valle medio inferior: 8472 ha.

Valle medio superior: 7334,5 ha.

Total del área: 26880,75 ha.

A pesar de las condiciones geográficas del valle, limitadas en comparación con otros valles costeńos, pues tiene pocas tierras y un río seco la mayor parte del año, en Supe se edificaron un 
mínimo de 18 centros urbanos, entre el litoral y los primeros $45 \mathrm{~km}$. La mayoría tiene arquitectura monumental (véase Figs. 1 y 2 )

Los establecimientos identificados en relación con las zonas ecológicas del valle son:

En el litoral:

Áspero, en la margen derecha

En el valle bajo:

Piedra Parada, en la margen izquierda,

El Molino, en la margen derecha,

En el valle medio inferior:

Margen derecha:

Limán

Era de Pando

Pando

Pueblo Nuevo

Cerro Colorado

Allpacoto

Margen izquierda:

Lurihuasi

Miraya

Chupacigarro

Caral

En el valle medio superior:

Margen derecha:

Peñico

Margen izquierda:

Huacache

Cerro Blanco

Capilla

Jaiva

EXTENSIÓN DE LOS ESTABLECIMIENTOS IDENTIFICADOS EN SUPE (véase Apéndice 2)

Sobre la base del cálculo de la extensión de los establecimientos, los hemos agrupado en cinco clases (véase Cuadro 1, Gráfico 1):

A. Establecimientos de 80 a 55 ha.:

Era de Pando

Caral

Pueblo Nuevo 55,01

\begin{tabular}{|l|c|}
\hline SITIOS DEL ARCAICO & HECTÁREAS \\
\hline Era de Pando & 79,74 \\
\hline Caral & 58,00 \\
\hline Pueblo Nuevo & 55,01 \\
\hline Lurihuasi & 37,80 \\
\hline Miraya & 36,00 \\
\hline Piedra Parada & 33,50 \\
\hline Allpacoto & 23,10 \\
\hline Peńico & 22,50 \\
\hline Aspero & 15,00 \\
\hline Chupacigarro & 9,00 \\
\hline Huacache & 7,59 \\
\hline El Molino & 6,96 \\
\hline Jaiva & 4,20 \\
\hline Pando & 1,95 \\
\hline Cerro Colorado & 0,98 \\
\hline Cerro Blanco & 0,80 \\
\hline Limán & 0,48 \\
\hline Capilla & 0,16 \\
\hline TOTAL & 392,77 \\
\hline
\end{tabular}

Cundro 1. Distribución jerdrquica de los establecimientos en el ualle de Supe por hectdreas.

B. Establecimientos de 40 a 30 ha.:

Lurihuasi

Miraya

Piedra Parada

C. Establecimientos de 25 a 15 ha.:

Allpacoto

Peńico

Áspero

15,00

D. Establecimientos de 10 a 5 ha.:

Chupacigarro 9,40

Huacache

El Molino

Jaiva 4,20

E. Establecimientos de menos de 5 ha.:

Pando 1,95

Cerro Colorado 0,98

Cerro Blanco 0,80

Limán 0,48

Capilla 0,16 


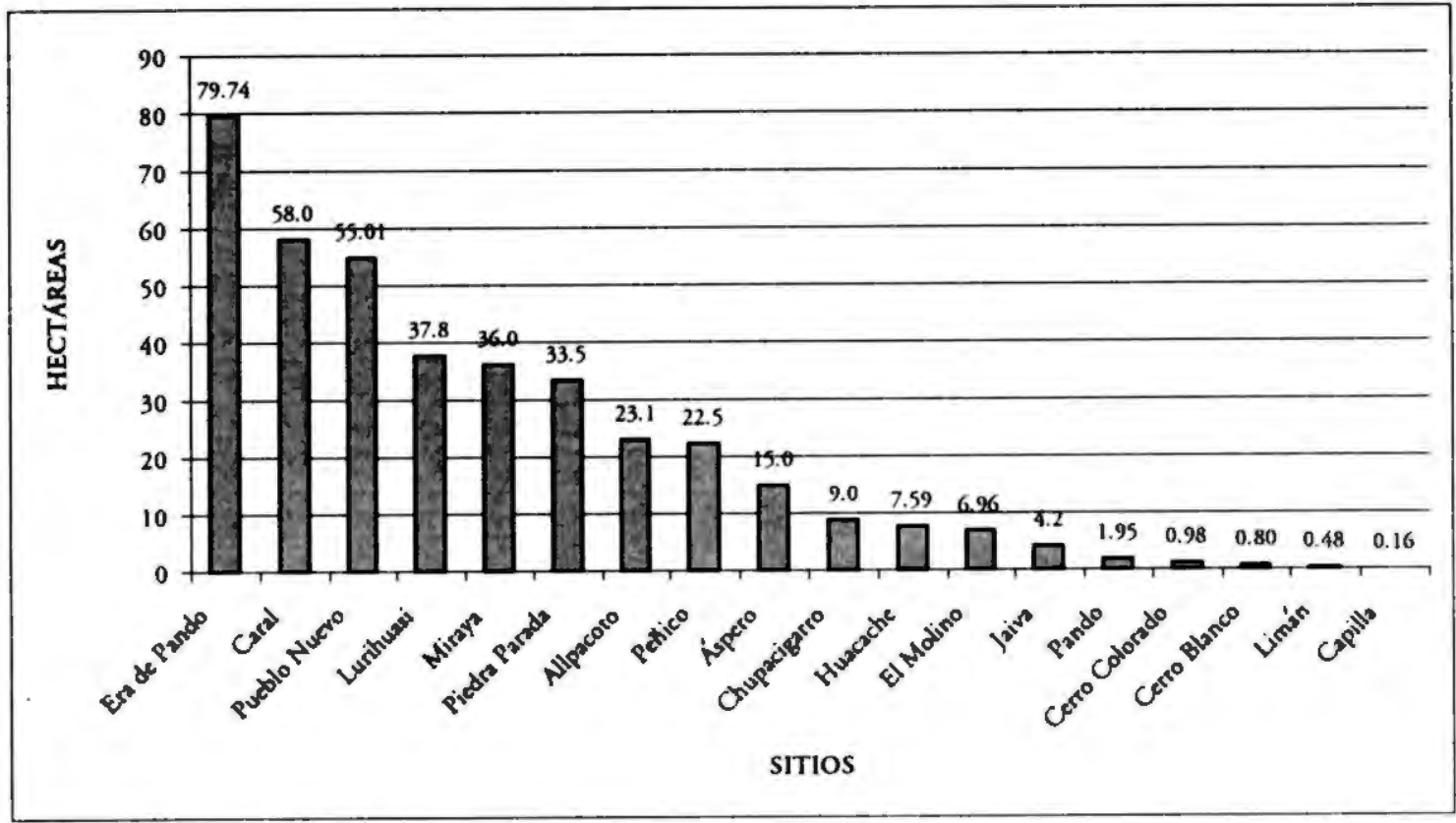

Gráfico I. Relación de sitios por hectdreas.

De esta información inferimos:

1. Tres establecimientos destacan por su extensión: Era de Pando, Caral y Pueblo Nuevo. Ellos ocupan el 49,07\% del área total construida en el valle. Un segundo lugar es ocupado por otros tres establecimientos: Miraya, Lurihuasi y Piedra Parada, que se emplazan sobre el $27,31 \%$ de la superficie total construida. Estos dos grupos ocupan el 76,38\% del área. Un tercer grupo está conformado por tres establecimientos, Allpacoto, Peñico y Áspero, que ocupa el 15,31\%. Le siguen dos grupos menores, uno con cuatro establecimientos, Chupacigarro, Huacache, El Molino y Jaiva, el otro con cinco establecimientos, Pando, Cerro Colorado, Cerro Blanco, Limán y Capilla, los cuales representan el $7,17 \%$ y $1,11 \%$, respectivamente. Es decir que 9 de 18 establecimientos ocupan el 8,28\% del área construida del valle. Estos resultados indican una distinción marcada en cuanto a extensión entre los establecimientos y ella debe reflejar diferencias socioeconómicas y funcionales significativas entre las cinco clases de centros urbanos.

2. Los centros urbanos más extensos y complejos se encuentran en dos zonas del valle:

Una primera concentración aparece en el valle medio inferior; allí se ubican los establecimien- tos en lugares muy cercanos entre sí y uno frente al otro. Se trata de la zona capital de Caral; esta ciudad es seguida hacia el oeste, uno a continuación del otro, por los centros urbanos de Chupacigarro, Miraya y Lurihuasi. Asimismo, este último se ubica frente a Pueblo Nuevo, en la otra margen del río, como Caral frente a Allpacoto. De los 6 establecimientos, 4 se hallan en las clases A y B, de mayor extensión, 1 en la clase C y 1 en la D. Aún cuando ocupaban el mismo sector del valle, estos centros urbanos habrían estado ordenados jerárquicamente entre sí y por encima de los ubicados en las otras zonas del valle.

Una segunda concentración, con características diferentes de la primera, se halla más en relación con el valle bajo, integrada por Era de Pando y Piedra Parada, en las márgenes derecha e izquierda, respectivamente, $y$ pertenecientes a las clases A y B. Estos centros urbanos habrían alcanzado importancia en un período posterior, al final del Arcaico, probablemente, en relación con la mayor productividad de las tierras irrigadas del valle bajo de Supe y de los valles vecinos.

3. Los centros urbanos más extensos están relacionados con vías de comunicación alternativas a los valles vecinos, a través de la serie de quebradas que pasan en forma perpendicular al va- 
lle. Los centros de la zona capital se encuentran vinculados: los de la margen derecha, a través de la quebrada de Allpacoto con el valle de Pativilca y Fortaleza; y los de la margen izquierda, por la quebrada de Chupacigarro con el valle de Huaura. Igualmente, Peñico enlaza la zona del alto Supe con los valles de Huaura y Chancay; y Huacache entre el valle medio $\mathrm{y}$ alto de Supe $\mathrm{y}$ el alto Pativilca. Era de Pando tiene conexión con el valle bajo de Supe y sus vecinos de Pativilca y Fortaleza; mientras Piedra Parada lo hace con la parte baja de los valles de Supe y Huaura (véase la Fig. 1 y Shady, en este mismo volumen).

\section{FUERZA DE TRABAJO INVERTIDA EN} LOS ESTABLECIMIENTOS DE SUPE (véase Apéndice 2).

En el Cuadro 2 y Gráfico 2, se pueden apreciar las siguientes clases de estructuras construidas:

A. Establecimientos que muestran la mayor cantidad y volumen de edificaciones:

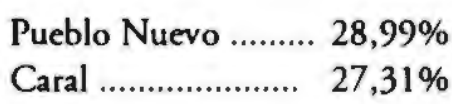

\begin{tabular}{|l|c|}
\hline \multicolumn{1}{|c|}{ SITIOS } & PORCENTAJE (\%) \\
\hline Pueblo Nuevo & 28,990 \\
\hline Caral & 27,306 \\
\hline Miraya & 12,853 \\
\hline Era de Pando & $\mathbf{8 , 5 3 8}$ \\
\hline Lurihuasi & 7,038 \\
\hline Allpacoto & 3,761 \\
\hline Pefico & 3,123 \\
\hline El Molino & 2,987 \\
\hline Piedra Parada & 1,670 \\
\hline Aspero & 1,654 \\
\hline Chupacigarro & 0,873 \\
\hline Huacache & 0,565 \\
\hline Cerro Blanco & 0,303 \\
\hline Cerro Colorado & 0,123 \\
\hline Jaiva & 0,103 \\
\hline Pando & 0,066 \\
\hline Limán & 0,046 \\
\hline Capilla & 0,001 \\
\hline TOTALES & 100,00 \\
\hline
\end{tabular}

Cuadro 2. Calculo del volumen construido en los establecimientos de Supe.
B. Establecimientos de segunda clase:

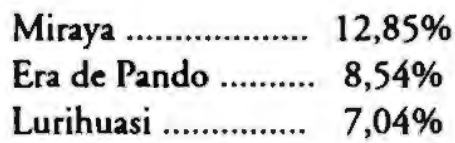

C. Establecimientos de tercera clase:
Allpacoto $3,76 \%$
Peñico $3,12 \%$
El Molino $2,99 \%$

D. Establecimientos de cuarta clase:

$\begin{array}{lr}\text { Piedra Parada } \ldots . . . . . & 1,67 \% \\ \text { Áspero } \ldots \ldots \ldots \ldots \ldots . . . . . . . .1,64 \%\end{array}$

E. Establecimientos de quinta clase:
Chupacigarro
$0,87 \%$
Huacache
$0,57 \%$

F. Establecimientos de sexta clase:

$\begin{array}{ll}\text { Cerro Blanco ....... } & 0,30 \% \\ \text { Cerro Colorado ..... } & 0,12 \% \\ \text { Jaiva ....................... } & 0,10 \% \\ \text { Pando ….............. } & 0,07 \% \\ \text { Limán ................... } & 0,05 \% \\ \text { Capilla .................. } & 0,001 \%\end{array}$

Este indicador pone en relieve que Caral y Pueblo Nuevo concentran el $56,30 \%$ del total de la fuerza de trabajo invertida. La segunda clase está integrada por Miraya, Era de Pando y Lurihuasi, con una inversión que asciende al $28,43 \%$ del total, que representa la mitad de la clase anterior. La tercera y cuarta clase, compuestos por cinco establecimientos, contienen el $13,18 \%$ del total. Es decir, una cuarta parte del trabajo fue invertido en la primera clase de establecimientos. Finalmente, la diferencia es muy notoria entre aquellos y la quinta y sexta clases pues, a pesar de estar integradas por ocho establecimientos, apenas exhiben el $2,08 \%$ del total de la fuerza de trabajo invertida.

Es importante resaltar la concentración de más de la mitad del total de fuerza de trabajo invertida en sólo dos establecimientos, Pueblo Nuevo y Caral, los que, además, ocupan más de la cuarta 


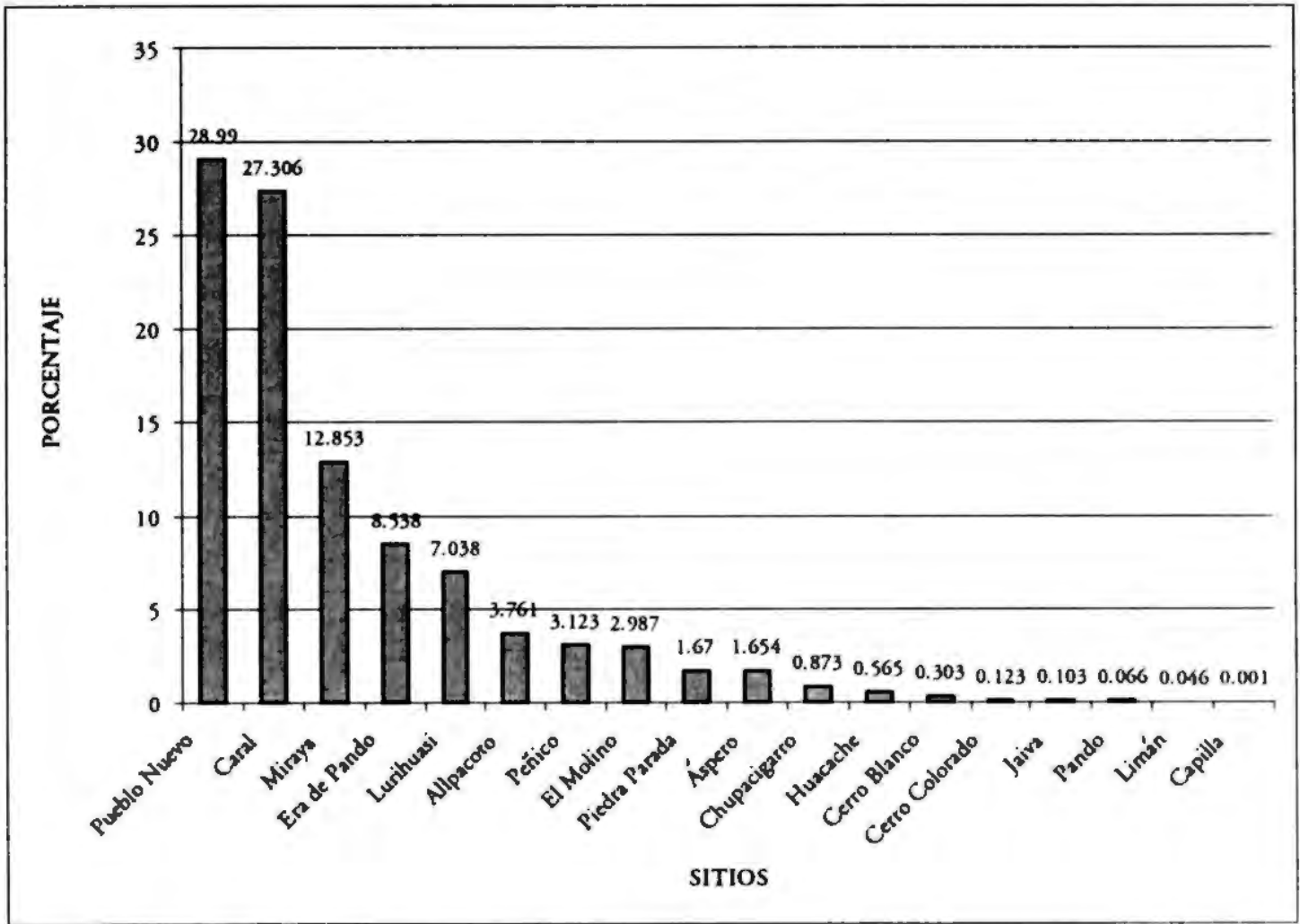

Gráfico 2. Inverión de fuerza de trabajo.

parte del total de hectáreas de los establecimientos construidos en el valle.

La segunda clase de establecimientos, que representa un poco más de la cuarta parte del total de la fuerza de trabajo invertida, aprovecha el $39,09 \%$ del total de hectáreas construidas, más de la tercera parte. Entre estas clases se encuentran los cinco principales establecimientos del valle de Supe: Caral, Pueblo Nuevo, Miraya, Lurihuasi y Era de Pando. De ellos, Caral y Pueblo Nuevo son de la primera clase, tanto por su extensión como por la fuerza de trabajo invertida en sus construcciones. Ambos se ubican en el valle medio inferior, en la margen izquierda y derecha, respectivamente.

DIVERSIDAD MORFOLÓGICA EN LA ARQUITECTURA DE LOS CENTROS URBANOS

Con el fin de complementar nuestra aproximación inicial a la complejidad funcional observada en los centros urbanos, hemos diferenciado los siguientes tipos de estructuras arquitectónicas (véase Cuadro 3, Gráfico 3):
1. Pirámide Mayor. La más destacada por su complejidad, volumen y dimensiones. Es un edificio complejo, de planta rectangular con dos alas laterales escalonadas $y$ una serie de adosamientos frontales. Si bien el edificio presenta un eje longitudinal de Este-oeste, todos los recintos están dispuestos en un eje principal norte-sur y el frente se orienta hacia el sur. En la parte baja, central y delantera del frontis se ubica una plaza circular hundida con anillo e ingresos opuestos a través de escalinatas que se alinean con el eje principal del edificio. De la plaza se asciende a la pirámide por una larga escalera que atraviesa los distintos niveles o plataformas hasta el atrio, ubicado en una de las plataformas de la cima.

Este tipo de estructura se encuentra en el extremo norte del centro urbano desde donde sobresale. Es posible que se trate de una forma desarrollada de la Pirámide Escalonada Grande, con la adición sucesiva de nuevos elementos y de remodelaciones hasta alcanzar una forma asimétrica $\mathrm{e}$ irregular.

Se han identificado sólo dos ejemplos de este tipo de edificio en todo el valle, ambos ubicados 
en el valle medio inferior, uno en Caral, en la margen izquierda, y el otro en Pueblo Nuevo, en la margen derecha. Ellos son, justamente, los dos centros urbanos de mayor extensión, complejidad y con la más grande inversión de fuerza de trabajo.

2. Pirámide. Edificios de planta cuadrangular y volumen piramidal, construidos a base de la superposición de plataformas. Presenta dos variantes: la pirámide escalonada, que muestra recintos en cada nivel elevado y la pirámide trunca, donde las paredes son oblicuas, empinadas y los recintos se ubican sólo en la cima.

Por su tamaño y volumen, tomando como referencia las dimensiones de la base, las hemos clasificado en:

Pirámide Grande. Cuando la base de la pirámide supera los 80 por $80 \mathrm{~m}$ lineales. En las pirámides escalonadas se ha llegado a contar hasta seis plataformas superpuestas. En la modalidad de pirámide trunca se puede apreciar la adición de módulos menores. Este tipo de estructura ocupa un lugar preferencial en los centros urbanos. $\mathrm{Ha}$ sido identificado en Caral, Pueblo Nuevo y Miraya.

Pirámide mediana. Las dimensiones que definen este tipo se encuentran entre 15 por 15 y los
79 por $79 \mathrm{~m}$. Se han apreciado estructuras de 3 a 5 plataformas superpuestas. Con frecuencia se halla formando parte de conjuntos de edificios y plazas, que comparten el mismo eje de orientación. Hay centros urbanos que tienen únicamente este tipo de estructuras o en asociación a una pirámide grande. Ha sido identificada en los centros urbanos de: Caral, Pueblo Nuevo, Miraya, Lurihuasi, Allpacoto, El Molino y Áspero.

Pirámide Pequeña. Presenta menos de 15 por $15 \mathrm{~m}$ y alcanza como máximo dos niveles superpuestos. Este tipo sólo se encuentra como anexo en relación con los edificios más grandes, con los que comparte el mismo eje de orientación. Se identificaron pirámides de este tipo en Caral, Pueblo Nuevo, Miraya, Lurihuasi, Áspero, El Molino y Allpacoto.

3. Estructura con plataformas secuenciales $y$ plaza. Se trata de un edificio de diseño planimétrico muy elaborado. Presenta una secuencia ligeramente ascendente de componentes arquitectónicos que se adosan en un espacio casi continuo siguiendo el mismo eje, norte-sur, uno después del orro. Se puede determinar dos variantes: una con plaza circular hundida con anillo y otra con plaza cuadrangular. Este tipo de estructura se halla en el extremo sur de los centros urbanos, orientado hacia el norte.

\begin{tabular}{|l|c|c|}
\hline \multicolumn{1}{|c|}{ TIPOLOGIA DE ESTRUCTURAS } & $\begin{array}{c}\text { NUMERO DE } \\
\text { ESTRUCTURAS }\end{array}$ & PORCENTAJE (\%) \\
\hline Pirámide escalonada pequeria & 44 & 26,67 \\
\hline Plataforma rectangular mediana & 25 & 15,15 \\
\hline Estructuras singulares & 20 & 12,12 \\
\hline Pirámide escalonada mediana & 17 & 10,30 \\
\hline Plataforma rectangular mediana & 14 & 8,48 \\
\hline Plataforma rectangular pequena & 10 & 6,06 \\
\hline Plaza circular en serie inscrita en ladera & 9 & 5,45 \\
\hline Plataforma cuadrangular pequefia & 7 & 4,24 \\
\hline Plaza circular inscrita con plataforma & 5 & 3,03 \\
\hline Estructura con plataformas secuenciales con plaza & 4 & 2,42 \\
\hline Pirámide escalonada grande & 3 & 1,82 \\
\hline Plataforma cuadrangular con plaza circular inscrita & 2 & 1,21 \\
\hline Pirámide mayor & 2 & 1,21 \\
\hline Plaza circular en secuencia vertical & 2 & 1,21 \\
\hline Plataforma cuadrangular grande & 1 & 0,61 \\
\hline TOTALES & 165 & 100,00 \\
\hline
\end{tabular}

Cuadro 3. Tipos de estructuras idensificadas en el valle de Supe. 


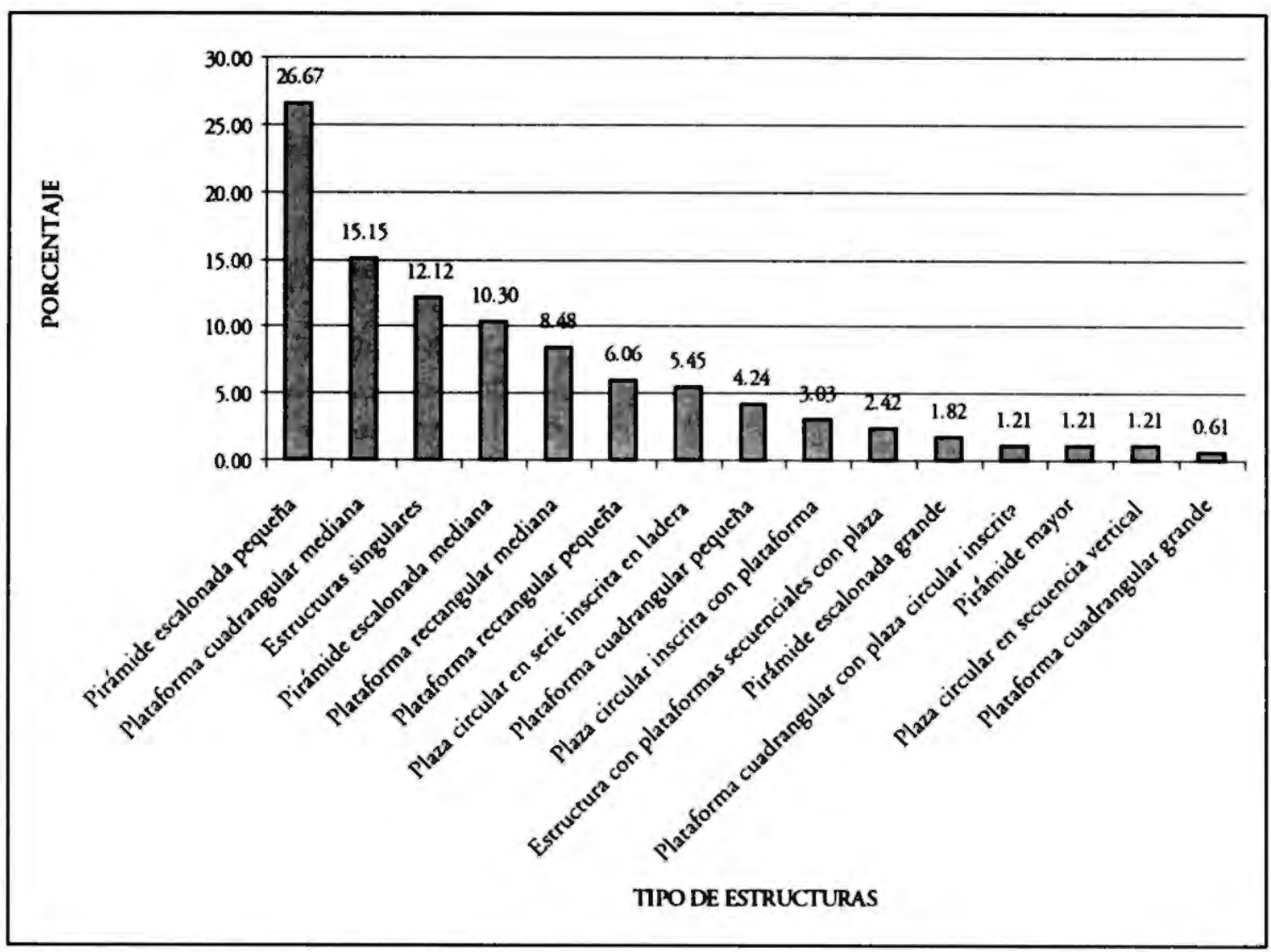

Gráfico 3. Distribución porcensual de los ripos de estrucruras.

El diseño se repite de uno a otro edificio como un patrón bien definido y denota una planificación y organización de los espacios muy sofisticada. Las dimensiones y volumen pueden variar pero la secuencia de los componentes arquitectónicos y la distribución de los espacios es casi la misma.

Este tipo de edificio ha sido identificado sólo en la margen izquierda, en Caral, Chupacigarro, Peñico y Cerro Blanco.

En Caral, la proporción de la plaza circular hundida es mayor que la del resto del edificio, lo que permite suponer una función privilegiada para este componente. En uno de los centros, sin embargo, se prescindió de este elemento y de la plataforma de ingreso, que fueron reemplazados por una plaza cuadrangular. Esta variante presenta semejanzas formales con las estructuras singulares, excepto en el tamaño.
La secuencia y distribución de los recintos en el espacio es la siguiente:

* Plataforma de ingreso. Ubicada en el extremo norte del edificio, una especie de puente o plataforma rectangular alargada, que conduce a la plaza. No se presenta en todos los edificios. Para el caso de Caral estaba flanqueada por una serie de nichos, dispuestos en hilera.

* Plaza circular hundida. Componente arquitectónico de planta circular hundida, inscrito en el interior de una plataforma circular. Se accede a ella a través de dos escalinatas opuestas que siguen el eje principal del edificio. En uno de los casos, dos columnas líticas flanquean los ingresos a la plaza. A este tipo de componente, que aparece en Caral con múltiples graderías concéntricas en la mitad interna de la plaza, se le ha denominado anfiteatro. 
La variante constituida por la plaza de planta cuadrangular, construida a nivel de la superficie, no presenta mayores elementos asociados y no le antecede la plataforma de ingreso.

Esta variante de plaza fue hallada sólo en el sitio de Cerro Blanco.

*Antesala. Siguiendo la secuencia se ubica un recinto anterior o delantero, de planta rectangular, con dos vanos opuestos en la parte central. Uno de ingreso desde la plaza y el otro de acceso al atrio.

*Atrio. Recinto importante dentro del edificio. Tiene forma cuadrangular, circundado por banquetas escalonadas, que reducen el espacio central, presidido por un fogón central. En el lado opuesto al vano (siguiendo el eje central principal) puede hallarse una escalinata empinada.

* Plataforma principal. Un espacio central de cierta elevación (Caral, Peńico), baja (Chupacigarro) o ubicada sobre una ladera (Cerro Blanco). Tiene planta rectangular alargada y contiene en la cima pequeñas habitaciones alineadas, a las que se accede por una escalinata ubicada en el centro. Este componente y el atrio constituyen la parte central y principal de todo el edificio.

* Plataformas Posteriores descendentes con algunos recintos (Caral y Peñico). También se puede encontrar un pequeño patio cuadrangular (Chupacigarro).

* Recintos Posteriores. Un conjunto de recintos aglutinados detrás de la plataforma posterior. Identificados en Chupacigarro y Cerro Blanco.

4. Estructuras singulares. Se trata de pequeños edificios planificados, de planta simétrica, que sigue el patrón de diseño de las estructuras de plataformas secuenciales con plaza pero a una escala reducida. No sólo los volúmenes y dimensiones son menores sino que también se pierden algunos elementos arquitectónicos. Representa una versión simplificada, que conjuga los rasgos principales.

Se han identificado tres variedades, diferenciadas por los elementos arquitectónicos que las componen como:
*Atrio con Plataforma Principal. Compuesto por estos dos componentes arquitectónicos. Primero un atrio cuadrangular escalonado con fogón central (puede presentar patio delantero), al que le sigue una plataforma baja. Ellos se pueden comunicar a través de una escalinata, banqueta o vano. Sólo se identificaron en Caral.

*Atrio con Antesala. Pequeña antesala de muros bajos $y$ atrio con un solo ingreso frontal $y$ fogón central. Se identificó en Peñico.

*Atrio aislado. Pequeńo recinto cuadrangular con fogón central y con doble ingreso a través de escalinatas opuestas. Presenta dos variantes, una con recinto interno, de planta cuadrangular $y$ otra de planta circular. Esta versión simplifica en su mínima expresión las variantes anteriores. Este tipo de estructura con frecuencia está asociado a las estructuras de plataformas secuenciales con plaza, con quien comparte el mismo eje de orientación. Ha sido reconocido sólo en la margen izquierda. Está ubicado en el extremo sur de los centros urbanos. Se identificó sólo en el establecimiento de Capilla.

5. Plataforma cuadrangular con plaza circular inscrita. Se caracteriza por presentar una estructura de planta cuadrangular de grandes dimensiones (más de 80 por $80 \mathrm{~m}$ ) pero baja, con subdivisiones internas, correspondientes a amplios recintos. El frontis principal puede estar tanto al norte (Piedra Parada) como al sur (Era de Pando). Adelante tiene adosada una plaza circular hundi$\mathrm{da}$, inscrita en una plataforma cuadrangular. La orientación de la estructura depende de su ubicación en determinada margen del valle, pues en ambos casos el edificio se encuentra en el extremo final del asentamiento, alejado del río, aunque se aprovechó el promontorio más alto desde donde se puede tener una buena visión del conjunto. En Era de Pando, ubicado en la margen derecha, la estructura se halla al fondo de la quebrada, orientada al sur; mientras que en Piedra Parada, en la margen izquierda, está sobre una loma y mira hacia el valle, al norte. Los dos sitios se hallan en el valle bajo o en el valle medio inferior y se encuentran entre los centros urbanos más grandes y complejos de esos sectores del valle. Asimismo, en ambos casos, esta estructura, (plataforma cuadrangular con plaza circular inscri- 
ta), constituye el principal componente arquitectónico.

6. Plataforma cuadrangular simple. Estructura poco elevada que no representa un volumen significativo a pesar que usaron rellenos constructivos para definir niveles. Muestra una serie de recintos sobre la superficie.

\section{Se reconocieron tres tamaños:}

* Plataforma Cuadrangular Grande. Se conoce un solo ejemplar, ubicado en Chupacigarro (pues a diferencia de Piedra Parada y Era de Pando no tiene plaza inscrita adosada), construido sobre una amplia loma, donde se aterrazaron las laderas. Sus dimensiones superan los 80 por $80 \mathrm{~m}$. En este caso, el frontis se orienta al oeste y los recintos son amplios como en los casos mencionados.

* Plataforma Cuadrangular Mediana. Aparecen formando núcleos de edificios, muy próximos unos de otros y que, además, comparten el mismo eje de orientación. Aprovecharon las largas terrazas formadas por las escorrentías en el fondo de las quebradas secas. Las elevaciones naturales son las que definen su orientación perpendicular al valle.

Este tipo de estructura se ha identificado en sitios como Peñico, Caral, Miraya, Lurihuasi, Era de Pando.
* Plataforma Cuadrangular Pequeña. Se encuentra formando núcleos acompañando al tipo anterior, a las plataformas rectangulares $y$ a las estructuras de plataformas secuenciales con plaza. Se han identificado en los sitios de Peńico, Caral, Chupacigarro, Miraya, Lurihuasi y Era de Pando.

7. Plataforma Rectangular. Estructura con la misma característica formal que el tipo anterior, sólo difieren en la forma de la planta. Esta clase de estructura integra los mismos núcleos de edificios y, por lo tanto, comparte con ellos el espacio y la orientación. Presenta una mayor variedad de dimensiones $y$ tiende a adosarse y superponerse una a otra lo que determina plantas de trazo irregular y con mayor complejidad interna. Destaca en el centro urbano de Miraya, donde integra un conjunto de edificios. A diferencia del tipo anterior sólo se reconocieron dos tamaños:

* Plataforma Rectangular Mediana. Presenta la mayor variabilidad de formas y tamaños. Tiende a ser más alta que los otros tipos de plataformas pero $\sin$ formar niveles escalonados. Los mejores exponentes se hallan en Caral, Miraya y Lurihuasi pero también se los puede encontrar en Peñico y Era de Pando.

* Plataforma Rectangular Pequeña. Representada por pocos ejemplos. Se la halla asociada a edificios grandes o conformando los núcleos anteriormente señalados. Identificada sólo en Miraya, Lurihuasi y Era de Pando.

Foto 2. Vista panordmica del sitio arqueológico Era de Pando.

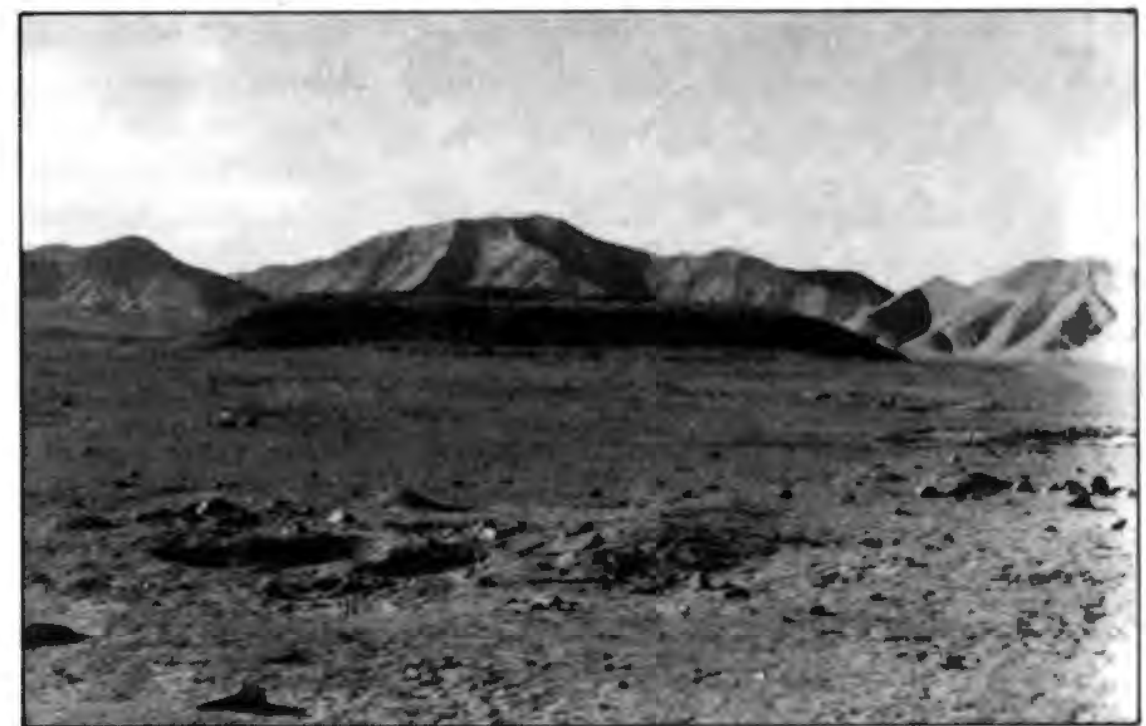


8. Plaza Circular en Serie inscrita en ladera. Compuesta por la sucesión de plazas circulares inscritas en plataformas cuadrangulares adosadas. Se ubican en la parte inferior de una ladera suave o empinada, modificada a través de un aterrazamiento escalonado. Ambos elementos arquitectónicos, plazas y terrazas, conforman una sola estructura, que posiblemente culmina o se relaciona con las plataformas o recintos ubicados en la cima de la ladera.

Si bien las dimensiones y el número de plazas pueden variar, todas presentan rasgos similares como una suerte de doble moldura en forma de media luna, ubicadas a cada lado y superpuestas sobre la plataforma, donde se inscribe la plaza circular. El ingreso a la plaza queda así en el centro, limitado por estas dos molduras. Otro rasgo compartido es la orientación del eje plaza-ladera escalonada, que sigue una dirección sur-norte, con la plaza al sur y las plataformas escalonadas al norte. Este eje se respetó aunque los centros urbanos estuvieran en márgenes opuestas.

Los sitios identificados con estructuras de este tipo son: Peñico (cinco plazas), Huacache (tres plazas) y Pueblo Nuevo (una plaza).

9. Plaza Circular Inscrita con Plataforma. Tipo no bien definido, que podría ser una variante del anterior. Consiste en una pequeña plaza circular inscrita en una plataforma cuadrangular pero delimitada en uno de los lados por una plataforma rectangular. A diferencia del otro tipo se encuentra en las cimas y en laderas altas $y$, quizás, por ello, se redujeron sus dimensiones. Todos los establecimientos identificados están en la margen derecha: Pando, Limán, Cerro Colorado.

10. Plaza Circular en Secuencia Vertical. Definida en base a un único ejemplo, identificado en el establecimiento de Jaiva. Se trata de la sucesión vertical de dos plazas circulares hundidas, que ascienden en una ladera baja y se intercomunican por medio de una larga escalinata. La sucesión de plaza-escalinata-plaza se alinea perpendicularmente al valle. En la cima, asociada a la segunda plaza, y siguiendo el mismo eje, se ubica una plataforma cuadrangular baja con una serie de recintos en su interior y detrás de ellos una plaza cuadrangular delimitada por un muro. Si bien las plazas no presentan el anillo concéntrico recuerdan a las de ese tipo.

11. Complejo Residencial. Se encuentra en medio de las estructuras de carácter público. Varía en relación con su ubicación dentro del centro urbano, en el tamaño de las casas y de los recintos que las conforman, en el material y las técnicas usadas en su construcción. Las excavaciones en Caral han permitido conocer que esta ciudad contiene, aparte de los tipos de arquitectura de carácter público, una serie de construcciones residenciales, que no son distinguibles desde la superficie. Suponemos que una situación similar ocurre en los otros centros urbanos; pero en tanto ellos no sean excavados no es posible consignar la arquitectura residencial. Anotamos, sin embargo que las variantes identificadas en Caral son:

* Casas construidas con piedra, compuestas de un conjunto de recintos y patios, ubicadas en relación con determinada pirámide.

* Casas construidas con material orgánico: palos de guarango, sauce y carricillos. Están ubicadas a cierta distancia de las pirámides pero con los accesos orientados hacia ellas.

* Casas hechas igualmente de palos y carricillos pero ubicadas cerca de las pirámides pequeñas, con los accesos orientados hacia éstas. Los recintos son de menor tamaño que en la variedad anterior.

* Casas pequeñas hechas con canto rodado. Están ubicadas en la parte marginal de la ciudad.

* Habitaciones aisladas, ubicadas en las inmediaciones de algunas estructuras públicas. Están hechas de palos, de los cuales sólo han quedado los orificios de éstos, de forma circular, de media luna o cuadrangular.

Si consideramos la inversión de fuerza de trabajo en los diversos tipos de estructura (véase Cuadro 4, Gráfico 4), estos indicadores muestran:

a) Que para la construcción de los cuatro primeros tipos compuestos por estructuras piramidades (Cuadros 4y 5) se invirtió el 80,11\% 


\begin{tabular}{|l|c|}
\hline \multicolumn{1}{|c|}{ TIPOLOGIA DE ESTRUCTURAS } & $\begin{array}{c}\text { PORCENTAJE DE FUERZA } \\
\text { DE TRABAJO }\end{array}$ \\
\hline Pirámide escalonada mediana & 25,07 \\
\hline Pirámide escalonada grande & 21,06 \\
\hline Pirámide mayor & 20,05 \\
\hline Pirámide escalonada pequefia & 13,93 \\
\hline Plataforma rectangular mediana & 7,65 \\
\hline Plataforma cuadrangular mediana & $\mathbf{4 , 6 0}$ \\
\hline Plataforma cuadrangular con plaza circular inscrita & 1,88 \\
\hline Plaza circular en serie inscrita en ladera & 1,79 \\
\hline Plataforma rectangular pequefia & 1,21 \\
\hline Estructura con plataformas secuenciales con plaza & 1,06 \\
\hline Plataforma cuadrangular pequefia & 0,64 \\
\hline Plataforma cuadrangular grande & 0,49 \\
\hline Estructuras singulares & 0,25 \\
\hline Plaza circular inscrita con plataforma & 0,22 \\
\hline Plaza circular en secuencia vertical & 0,10 \\
\hline TOTALES & $\mathbf{1 0 0 , 0 0}$ \\
\hline
\end{tabular}

Tabla 4. Tipos de estructuras en relación con el volumen de fuerza de srabajo invertido.

del total de fuerza de trabajo. Este tipo de edificio se encuentra en mayor frecuencia en los sitios de Áspero, El Molino, Pueblo Nuevo, Allpacoto, Caral y Miraya. En una siguiente categoría a se pueden agrupar las estructuras compuestas por plataformas de diversos tipos con un 14,62\%, estas se focalizan en sitios como Era de Pando, Piedra Parada, Lurihuasi, Miraya y Caral. Finalmente, aislamos dos grupos menores que apenas concentran el $3,16 \%$ y el $2,11 \%$ de la fuerza de trabajo. Por un lado tenemos las estructuras con plataformas secuenciales con plaza y estructuras singulares y por otro lado los tipos compuestos por plazas solas respectivamente. Los tipos de ambos grupos se pueden hallar en forma aislada o al interior de centros urbanos principales.

b) En el Cuadro 5 se puede apreciar una tendencia hacia la conformación de dos modelos básicos de centro urbano, uno compuesto principalmente por los diversos tipos de pirámides y el otro por los diversos tipos de plataformas. En el primer grupo el edificio más relevante es la pirámide mayor, mientras que en el otro lo conforma la plataforma cuadrangular con plaza circular inscrita.

c) El desenvolvimiento de diversas funciones en cada establecimiento al margen de su extensión y tamaño. Las evidencias de Caral, con una morfología variada de estructuras, tanto de carácter público como privado, sugiere el uso multifuncional de los centros urbanos, así como la identificación de diversos sectores con viviendas residenciales de diferente dimensión o material constructivo, que indica las distinciones sociales de sus ocupantes.

d) Una mayor representación de los distintos tipos constructivos en los centros urbanos más extensos. Variabilidad que debe corresponder a la realización en ellos de, igualmente, un número más amplio de funciones.

e) Distinciones en las diversas clases de centros urbanos, que estarían en concordancia con un sistema de establecimientos jerarquizado con diferencias funcionales y con separaciones temporales.

f) Diferencias en las construcciones domésticas dentro de una ciudad como Caral, en cuanto a ubicación, dimensiones o material constructivo. Ellas evidenciarían distinciones sociales jerárquicas entre sus habitantes.

\section{SECUENCIA OCUPACIONAL DE CARAL- SUPE}

Sobre la base de la información obtenida en Caral se pueden plantear tres grandes períodos:

1. El más antiguo, cuando se habilitaron las tierras de cultivo, mayormente asociadas a 
humedales, en función de las cuales se construyeron los centros urbanos, como asientos de los linajes y se edificaron las estructuras piramidales en Áspero, El Molino, Allpacoto, Pueblo Nuevo, Caral, Miraya. Los jefes de linajes conducirían la vida y las actividades de los habitantes de cada asentamiento, así como las relaciones entre los varios asentamientos (véase Shady, en este volumen). En este período se pueden identificar varias fases, a través de las cuales crecieron los centros en extensión y monumentalidad, a la par que se hacía más compleja la organización social. Las estructuras públicas muestran espacios cerrados para ceremonias privadas de una élite, representada por las cabezas de linajes.

2. Un segundo período, de fuertes cambios, cuando se introdujeron las plazas circulares como espacios públicos abiertos, se empleó la shicra o bolsas de fibra, rellenas con piedras, como material constructivo. Se transportaron piedras de gran volumen y se elevaron o ampliaron las construcciones piramidales con in- gente inversión de fuerza de trabajo organizada (pirámide mayor, estructuras con plataformas secuenciales con plaza y estructuras singulares). Período que tuvo, asimismo, varias fases, durante las cuales crecieron en monumentalidad los centros urbanos. Alcanzaron gran prestigio Caral y los otros centros aglutinados en el sector inferior del valle medio, Pueblo Nuevo, Miraya, Lurihuasi, que debió erigirse como la zona capital dominante de la serie de establecimientos jerarquizados. Se construyeron nuevos centros urbanos en Peńico, Chupacigarro, Cerro Blanco, Jaiva y Capilla. Es el período de formación del Estado prístino.

3. Un tercer período cuando crecieron en extensión y volumen los centros urbanos, como Caral, Miraya, Lurihuasi, Era de Pando y Piedra Parada, mediante la construcción de una serie de estructuras a base de plataformas bajas y se edificaron plazas circulares inscritas en plataformas cuadrangulares. Es interesante observar, asimismo, que las plataformas contienen una serie de

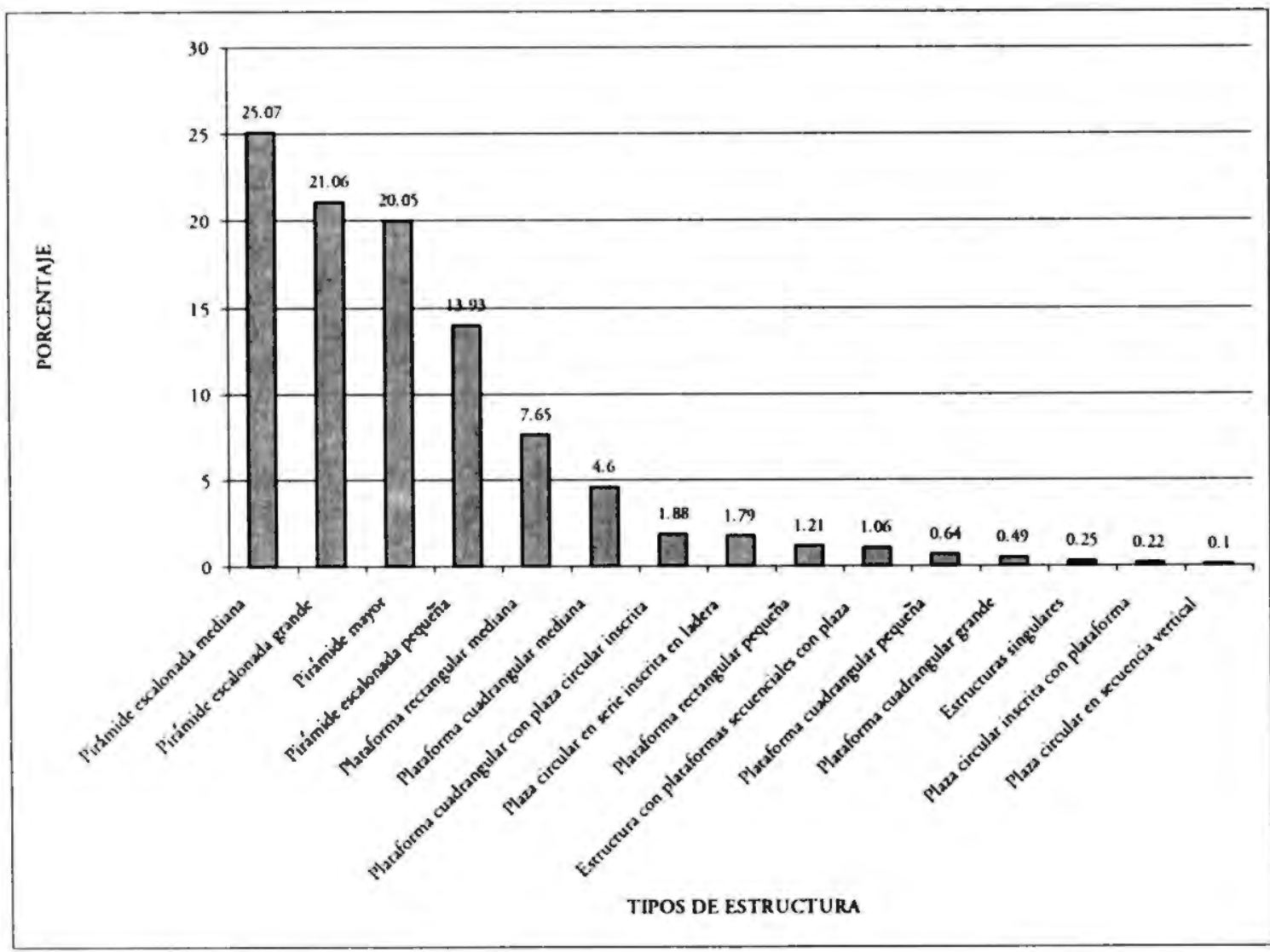

Grifico 4. Distribución de la fuerza de trabajo en los diferentes tipos de estructura. 


\begin{tabular}{|c|c|c|c|c|c|c|c|c|c|c|c|c|c|c|c|c|c|c|c|}
\hline & $\frac{9}{4}$ & 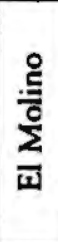 & 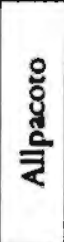 & 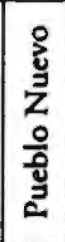 & ㄱํํ & 蛋 & 或 & 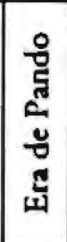 & 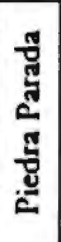 & 总 & 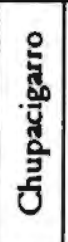 & 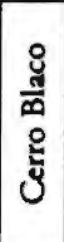 & $\frac{a}{\overline{\frac{\alpha}{3}}}$ & 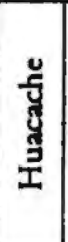 & $\begin{array}{l}\text { 원 } \\
\text { 응 } \\
\text { 연 }\end{array}$ & 茎 & 옳 & 预 & TOTALES \\
\hline Pirámide escalonada pequeña & 5 & 3 & 9 & 11 & 6 & 8 & 2 & & & & & & & & & & & & 44 \\
\hline Pirámide escalonada mediana & & 1 & 2 & 5 & 2 & 3 & 4 & & & & & & & & & & & & 17 \\
\hline Pirámide escalonada grande & & & & 1 & 1 & 1 & & & & & & & & & & & & & 3 \\
\hline Pirámide mayor & & & & 1 & 1 & & & & & & & & & & & & & & 2 \\
\hline Estructura con plataformas secuenciales con plaza & & & & & 1 & & & & & 1 & 1 & 1 & & & & & & & 4 \\
\hline Estructuras singulares & & & & & 11 & & & & & 1 & 7 & & 1 & & & & & & 20 \\
\hline Plaza circular en secuencia vertical & & & & & & & & & & & & & & & & 2 & & & 2 \\
\hline Plaza circular en serie inscrita en ladera & & & & 1 & & & & & & 5 & & & & 3 & & & & & 9 \\
\hline Plaza circular inscrita con plataforma & & & 1 & & & & & & & & & & & & 2 & & 1 & 1 & 5 \\
\hline Plataforma cuadrangular grande & & & & & & & & & & & 1 & & & & & & & & 1 \\
\hline Plataforma cuadrangular con plaza circular inscrita & & & & & & & & 1 & 1 & & & & & & & & & & 2 \\
\hline Plataforma cuadrangular pequeña & & & & & & & & 6 & 1 & & & & & & & & & & 7 \\
\hline Plataforma rectangular pequeña & & & & & & & & 10 & & & & & & & & & & & 10 \\
\hline Plataforma rectangular mediana & & & & & 2 & 7 & 3 & & 1 & 1 & & & & & & & & & 14 \\
\hline Plataforma cuadrangular mediana & & & & & 4 & & 15 & 4 & 1 & 1 & & & & & & & & & 25 \\
\hline TOTALES & 5 & 4 & 12 & 19 & 28 & 19 & 24 & 21 & 4 & 9 & 9 & 1 & 1 & 3 & 2 & 2 & 1 & 1 & 165 \\
\hline
\end{tabular}

Cuadro 5. Tendencia de los sitios a agruparse en dos modelos de centro urbano: En uno, predominan los tipos de pirdmide y en el otro, los tipos de plataforma. 
Foto 3. Vista panordmica del sitio arqueológico de Cerro Colorado.

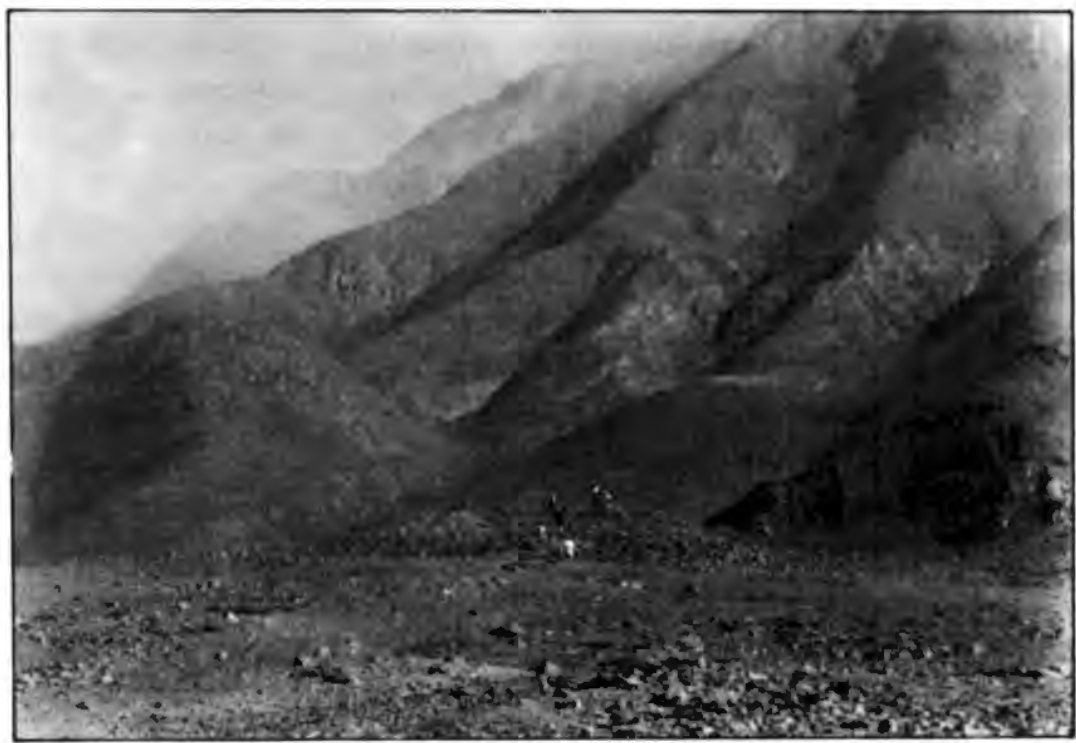

recintos pequeños, que podrían haber funcionado como depósitos, evidenciando una mayor administración de bienes.

Se reprodujo en el resto del valle este elemento de plazas inscritas, tal como se aprecia en Limán, Pando, Cerro Colorado, Huacache, Peñico. Perdieron importancia anteriores centros urbanos como Áspero, El Molino, Allpacoto y Pueblo Nuevo. Se puede notar que la mayoría de establecimientos se hallaba en la margen izquier$\mathrm{da}$, en relación, quizás con la importancia que iba adquiriendo la agricultura en el valle vecino de Huaura, de mayor productividad, así como los valles bajos norteños, en el caso de Era de Pando.

\section{UNIDAD CULTURAL Y POLÍTICA EN LA DIVERSIDAD SOCIOECONÓMICA}

Comparativamente, se puede observar que a la par que los establecimientos muestran diversos componentes, de carácter público y privado, ellos también contienen algunas estructuras arquitectónicas que se repiten en los establecimientos identificados a lo largo de los primeros $45 \mathrm{~km}$ del valle de Supe, en cuanto a diseño planimétrico, elementos y técnicas constructivas. Esto permite inferir que si bien se realizaban actividades económicas, políticas y religiosas en cada centro urbano, éstos habían sido integrados al sistema socioeconómico y político del Estado prístino.
La mayoría de los centros urbanos más extensos y monumentales se halla aglutinada en el sector medio inferior del valle, uno al lado del otro o frente a frente, en cada margen del río, a una distancia de 1,5 a $2 \mathrm{~km}$ entre sí. Caral versus Pueblo Nuevo son los más notables, en las márgenes izquierda y derecha del valle; ambos se encuentran a unos $5,5 \mathrm{~km}$ de distancia, ocupan una cuarta parte del total de hectáreas de los establecimientos construidos en el valle de Supe y concentran el $56,30 \%$, más de la mitad del total del porcentaje de fuerza de trabajo invertida en ese valle. Por todos estos indicadores, extensión, tamaño y volumen de la arquitectura pública de los dos sitios, se infiere la posición preeminente que ellos tuvieron en el sistema político y el poder de la élite gobernante del naciente Estado, que lo conducía. Como bien se ha señalado: "la arquitectura temprana monumental, vista en la costa del Perú como también en muchas otras partes del mundo, es una manifestación fisica de una estructura de poder estatal emergenten (Haas, 1987: 32).

Cabe señalar la presencia de un conjunto de establecimientos en el valle medio inferior, ubicados en secuencia espacial: Lurihuasi, Miraya, Chupacigarro, Caral, en la margen izquierda y Pueblo Nuevo, Allpacoto, en la margen derecha, construidos a corta distancia entre sí, de 1 a 2 $\mathrm{km}$, uno seguido del otro (viniendo desde el oeste, de Lurihuasi a Miraya hay 1 km; de Miraya a 
Chupacigarro $1 \mathrm{~km}$; de Chupacigarro a Caral 1 $\mathrm{km}$. Cruzando el río, de Lurihuasi a Pueblo Nuevo hay $2 \mathrm{~km}$ y de Caral a Allpacoto $1,5 \mathrm{~km}$ ). Estos centros urbanos debieron funcionar en algunos períodos como una zona capital que dominaba la jerarquía de establecimientos, dentro de un modelo de conexión, similar al planteado por Stark para Mesoamérica (Stark, 1999: 201-205). Con excavaciones futuras en algunos de ellos se tendrán evidencias para precisar las funciones que cada cual desempeńó en el conjunto.

Por otro lado, es interesante observar la distancia que separa los establecimientos principales, ubicados en las diferentes zonas ecológicas: De Áspero, en el litoral, a El Molino, en el valle bajo, hay $8,5 \mathrm{~km}$ y a Piedra Parada 7,5 km. Desde allí, si seguimos por la margen derecha, del Molino a Era de Pando, en el inicio del valle medio inferior hay $8 \mathrm{~km}$; de Era de Pando a Pueblo Nuevo $5,5 \mathrm{~km}$; de Pueblo Nuevo a Allpacoto $4 \mathrm{~km}$ y de Allpacoto a Huacache, éste último ya en el valle medio superior, $10 \mathrm{~km}$, siguiendo el río y un poco menos si se entra por el atajo de Las Minas. Por la margen izquierda tenemos que, de Piedra Parada, en el valle bajo, a Lurihuasi en el valle medio inferior hay $14 \mathrm{~km}$; de Caral a Peñico, éste último en el valle medio superior, $10,5 \mathrm{~km}$; $\mathrm{y}$ de Peñico a Cerro Blanco $4 \mathrm{~km}$ o de Cerro Blanco a Jaiva $4 \mathrm{~km}$. Finalmente, de Piedra Parada a Era de Pando se tiene $10 \mathrm{~km}$; y de Era de Pando a Caral $9,5 \mathrm{~km}$.
Se nota por esta información que los establecimientos distribuidos en el interior de una misma zona ecológica se hallan a unos $4 \mathrm{~km}$ de distancia, salvo en la zona capital, donde están a 1 ó $2 \mathrm{~km}$. En cambio, hay distancias de 7,5 a $10 \mathrm{~km}$ entre centros ubicados en diferentes zonas ecológicas. No conocemos todavía el significado de esta separación espacial; podríamos suponer que $4 \mathrm{~km}$ sería el espacio de tierras cultivadas bajo el control de una comunidad y que la separación mayor entre establecimientos de diferentes zonas correspondería a divisiones administrativas de base económica. Quizás en este espacio se encontraban las tierras de beneficio común, para las huacas, el Estado, etc. Es posible que existieran más relaciones de integración o conflicto entre los centros vecinos que entre aquellos ubicados a medio o un día de camino, donde las vinculaciones tendrían diferente significado.

Como se ha indicado, la extensión espacial, volumen de fuerza de trabajo invertida en las construcciones y la variabilidad morfológica de éstas han permitido identificar, por lo menos, cinco clases de centros urbanos; distinción que debe corresponder a una jerarquía de los establecimientos con significación sociopolítica. La presencia de un mayor número de tipos de estructuras arquitectónicas, en particular acentuada en los centros urbanos de las tres primeras clases, debió estar en concordancia con un mayor número de funciones que cumplían sus habitantes.

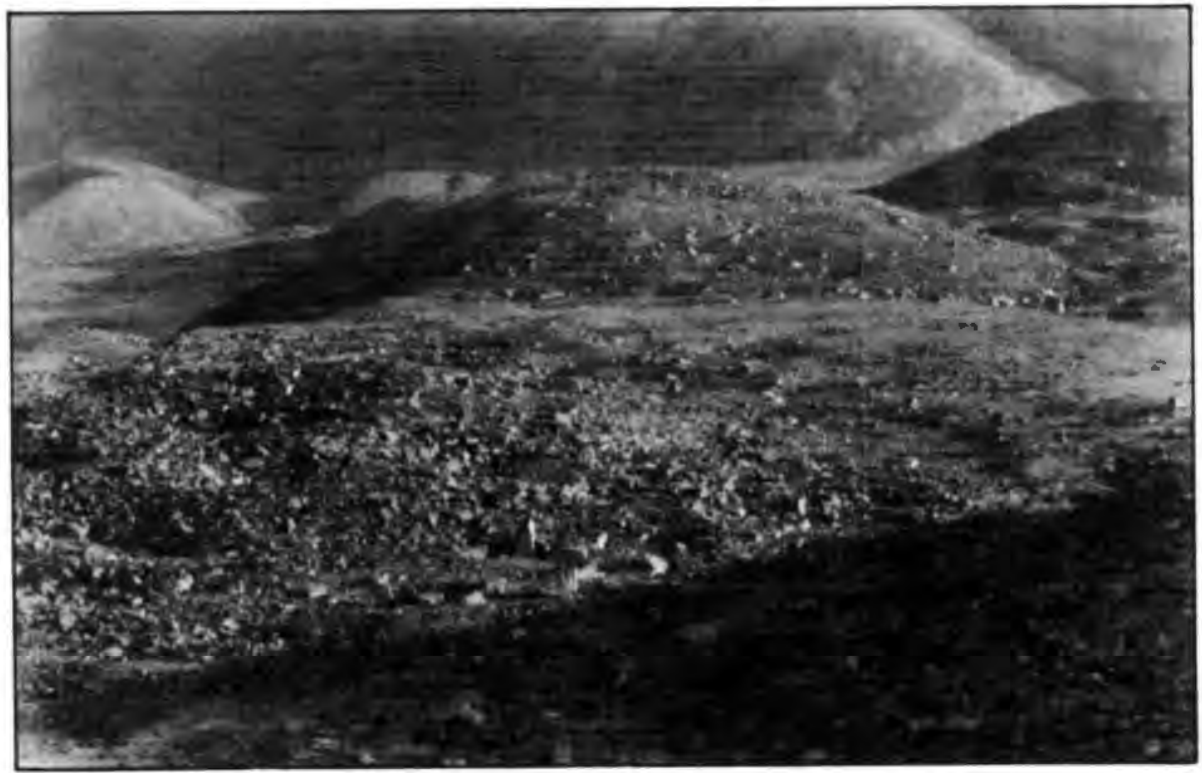

Foro 4. Vista panordmica del sitio arqueológico de Miraya. 
Por todo ello, podemos plantear la existencia en Supe durante el Arcaico Tardío de una sociedad diferenciada por actividades económicas especializadas, por su distinta ubicación en estratos sociales jerarquizados y por su distribución en centros urbanos integrados en un sistema, igualmente, jerarquizado. Esta diferenciación habría derivado de la posición que se ocupaba en el proceso productivo general, de las valoraciones dadas a las funciones dentro del sistema socioeconómico y a la participación que se tenía en la distribución del excedente producido.

El excedente productivo, acumulado por la sociedad de Supe, habría servido para el mantenimiento del sector de la población dedicado al estudio de los astros y a la confección del calendario agrícola; al cálculo matemático y al diseño geométrico, aplicados a la agrimensura y a la edificación de monumentales obras arquitectónicas; al cálculo de resistencia de materiales; al manejo organizado de la población; a la conducción de las ceremonias y rituales y al mantenimiento de las relaciones políticas, administrativas y comerciales entre centros urbanos cercanos o distantes. Actividades todas que justificaba su existencia. Éstos fueron los especialistas y los que conformaron la élite de poder en el Estado prístino.

La riqueza generada por la sociedad de Supe, y por las sociedades del área que el Estado prístino de Supe pudo concentrar, habría hecho posible la inversión de ingente fuerza de trabajo en la construcción y remodelación periódica de las es- tructuras monumentales. La productividad lograda únicamente por la población de Supe no explicaría la obra realizada en sus diferentes centros urbanos.

\section{CONCLUSIONES}

1. En el territorio andino hubo, como en otras partes del mundo aunque en un espacio más cerrado, una amplia variedad de adaptaciones culturales, pero a distancias relativamente próximas, así como diferentes trayectorias y ritmos de desarrollo sociopolítico. Sin embargo, durante el Arcaico Tardío, las sociedades asentadas en las varias regiones del área norcentral mostraron un gran dinamismo en sus actividades socioeconómicas, políticas y culturales. Poseedoras de culturas distintivas, habían alcanzado excedentes productivos y un nivel de organización comunal que les permitía la construcción de pequeños centros urbanos y su participación en una esfera de interacción interregional.

2. La población de Supe, establecida, asimismo, en centros urbanos, tanto en el litoral como en el valle, cerca de uno de los mares más ricos del planeta y en una zona favorecida por humedales, había desarrollado una economía productiva, internamente complementaria, agrícolapesquera. Al intenso comercio entre ambos grupos de comunidades especializadas, que generó una esfera económica supracomunal y excedentes productivos en escala mayor, se adicionó la conexión interregional dentro del área norcentral,

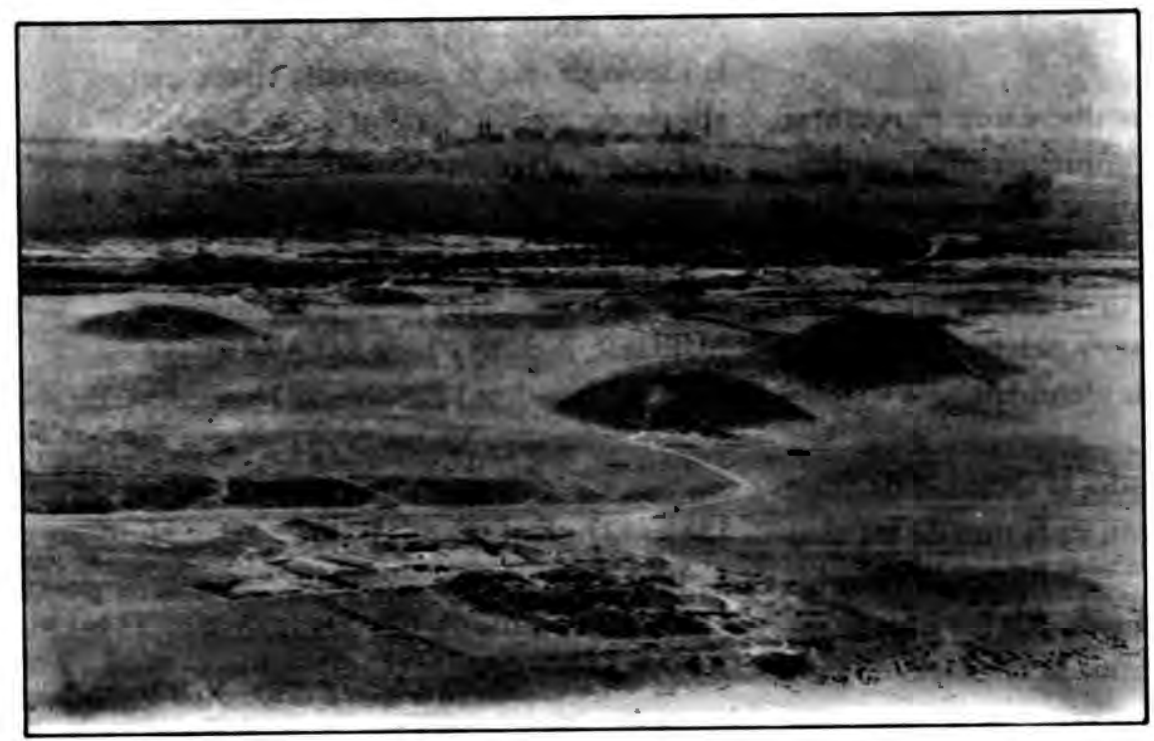

Foro 5. Vista panordmica del sitio arqueológico de Caral. 
Foto 6. Fases constructivas de un recinto del sitio arqueológico de Chupacigarro.

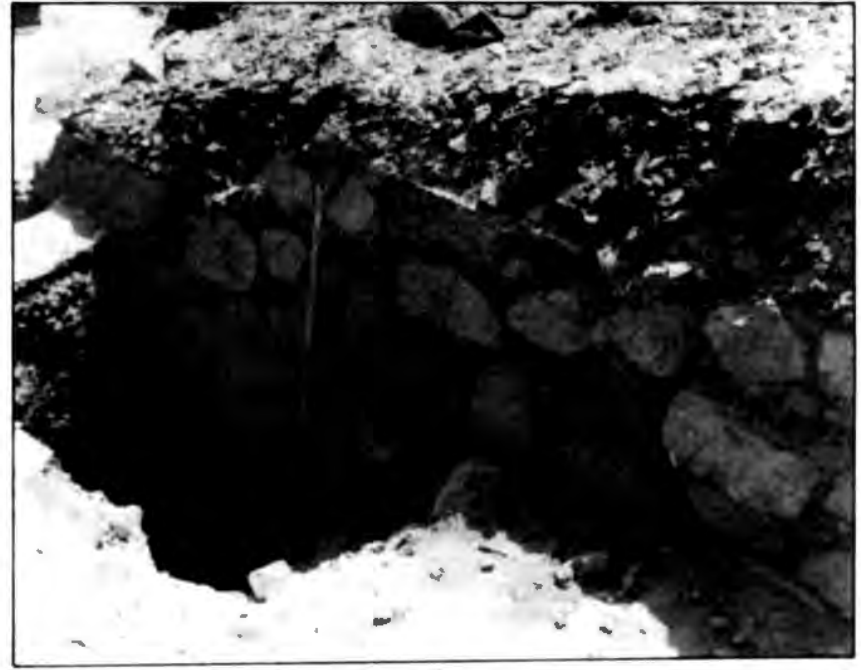

fomentada, además, por la ubicación estratégica de este valle. Aquellas y estas condiciones favorecieron la formación de clases sociales y le permitieron a la sociedad de Supe captar en su beneficio los excedentes producidos en el área, así como fortalecer su proceso de integración política, bajo la forma de un gobierno estatal.

3. Los 18 establecimientos con arquitectura monumental, identificados entre la boca del río Supe y Jaiva, en un valle pequeño, con escasas tierras y un río de régimen irregular, seco la mayor parte del año, difícilmente hubieran sido construidos sobre la base de la productividad lograda únicamente por sus pobladores. La cuantiosa inversión de trabajo en obras monumentales habría sido sustentada por la producción de las poblaciones de los otros valles, que el Estado prístino supo captar.

4. Los centros urbanos albergaron estructuras públicas de varios tipos, construcciones residenciales de carácter doméstico, talleres, etc. Ellos fueron multifuncionales; autosuficientes en su producción económica; tuvieron su propio gobierno; así como sus dioses y prácticas religiosas, en los que sustentaban su identidad.

5. En un primer período, la sociedad de Supe construyó centros urbanos, cada uno de los cuales congregaba a un conjunto de linajes. Era conducido por un consejo, integrado por los jefes de éstos, y manejaba un determinado territorio de producción. En un segundo período, con la formación de estratos sociales jerarquizados y del Estado prístino, se definió un sistema de centros urbanos diferenciados, entre los cuales destacaban los ubicados en la zona capital de Caral. Se construyeron plazas circulares de función pública y se invirció una ingente fuerza de trabajo en las construcciones monumentales. En un tercer período, se amplió el número de centros urbanos en el valle de Supe y se generalizó el modelo de plazas circulares inscritas. Adquirieron prestigio los centros urbanos ubicados más cerca del valle bajo.

6. El valle de Supe fue el asiento donde se formó por primera vez en la historia peruana un gobierno estatal. Una clase social dominante ejerció el poder por sobre todas las comunidades o pachacas, asentadas en centros urbanos y su influencia se extendió al área norcentral durante el Arcaico Tardío. Sin embargo, el modelo estatal y la ideología que lo sustentaba trascenderían más allá de ese espacio y tiempo.

\section{BIBLIOGRAFÍA}

\section{BURGER, Richard y Lucy SALAZAR}

1980 "Ritual and Religion at Huaricoton. En Archacology 32, pp. 26-32.

1985 "The Early Ceremonial Center of Huaricoto". En Early Ceremonial Architecture in the Andes, editado por Ch. Donnan, pp. 111-138. Washington, D.C.: Dumbarton Oaks. 
FELDMAN, Robert

1980 Aspero, Peru: Archisectura, Subsistence Economy andOther Artifacts of a Preceramic Maritime Chiefdom. Tesis. Harvard University.

FUNG, Rosa

1988 "The Late Preceramic and Initial Period". En Peruvian Prehistory editado por R. Keatinge, pp. 67-96. Cambridge and New York: Cambridge University Press.

\section{GRIEDER, T. et al.}

1988 La Galgada, Peru. A Preceramic Culture in Transition. Austin: University of Texas Press.

HAAS, Jonathan, Shelia POZORSKI y Thomas POZORSKI (editores)

1987 The Origins and Development of the Andean State. New York: Cambridge University Press.

KOLATA, Alan L.

1997 "Of Kings and Capitals. Principles of Authority and the Nature of Cities in the Native Andean Staten. En The Archaeology of CityStates, editado por Deborah L. Nichols y Thomas H. Charlton. Washington y London: Smithsonian Institution Press.

LYNCH, Thomas

1980 Guitarrero Cave. Early Man in the Andes. New York Academic Press.

QUILTER, Jeffrey

1989 Life and Death at Paloma. Society and Morruary Practices in Precenamic Peruvian Village. lowa City: University of Iowa Press.

SHADY, Ruth

1997 La Ciudad Sagrada de Caral-Supe en los Albores de la Civilización en el Peri. Lima: UNMSM.

1999 «El Sustento Económico del Surgimiento de la Civilización en el Perúw. En Boletín del Museo de Arqueologia y Antropologia de la UNMSM, аño 2, No 11, Lima, pp 2-4

1999b "Los Orígenes de la Civilización y la Formación del Estado en el Perú: Las Evidencias Arqueológicas de Caral-Supe (Primera Parte). En Boletín del Museo de Arqueología y Antropologia de la UNMSM, аño 2, No 12 , Lima, pp. 2-4. 2000a *Los Orígenes de la Civilización y la Formación del Estado en el Perú: Las Evidencias Arqueológicas de Caral-Supe (Segunda Par(e).. En Boletín del Museo de Anqueologia y Antropología de la UNMSM, año 3, No 2, Lima, pp. 2-7.

2000b «ecuperando la Historia del Altar del Fuego Sagradow. En Boletin del Museo de Arqueologia y Antropología de la UNMSM, аño 3. No 4, Lima, pp. 2-15.

SHADY, Ruth y Miriam GONZÁLEZ

2000 "Tumba Circular Profanada de la Ciudad Sagrada de Caral-Supew. En Boletín del Museo de Anqueologia y Antropologia de la UNMSM, año 3, No5, Lima, pp. 2-9.

SHADY, Ruth, Marco MACHACUAY y Rocío ARAMBURÚ

2000 "La plaza circular del Templo Mayor de CaralSupe: Su presencia en Supe y en el Área Norcentral del Perún. En Boletin del Museo de Arqueologia y Antropología de la UNMSM, año $3, \mathrm{~N} \cdot 8$, Lima.

STARK, Barbara L

1999 „Formal Architectural Complexes in South.Central Veracruz, Mexico: A Capital Zone?. En Journal of Field Anchaeology, vol. 26.

\section{ZECHENTER, Elzbieta}

1988 Subsistence strategies in the Supe Valley of the Peruvian Central Coast during the Complex Precenamic and Initial Periods. Tesis. Los Angeles: University of California. 


\section{APÉNDICE 1}

\section{RELACIÓN DE ESTABLECIMIENTOS DEL VALLE DE SUPE}

\section{Áspero (10H-01, coordenadas 200500 E y 8 803000 N).}

Ubicado en el litoral. Conjunto de montículos correspondientes a estructuras de diversos tipos, pirámides, plataformas, recintos habitacionales, etc. (Fig. 3).

\section{Conservación}

Muy deteriorado por excavaciones arqueológicas y buscadores de tesoros. Actualmente, viene siendo usado como basurero del distrito de Supe Puerto.

\section{Piedra Parada (111-01, coordenadas 207000 E r 8799500 N).}

\section{Ecologia}

Ubicado en la margen izquierda, en el valle bajo. Las principales estructuras se encuentran sobre un espolón rocoso y en la parte media alta de la hondonada, alejadas del fondo del valle, cruzado por una serie de canales o sangrías de drenaje, que revelan una zona pantanosa. Un estanque cercano da vida a la flora y la fauna propias del lugar (Fig. 4).

El componente perteneciente al período Arcaico tiene dos sectores principales y otros menores:

En la hondonada denominada El Tutumo, un cono de deyección, encima del canal de cemento, que lo ha alterado en parte, se halla un pequeño complejo de recintos, construidos con cantos rodados, asociado a un camino.

En la siguiente hondonada se ubica Piedra Parada propiamente, que presenta los siguientes sectores:

A1. En el ingreso a la hondonada desde el Este se encuentra una construcción de canto rodado, de planta semicircular, con terrazas en dirección al valle. En un pozo de huaqueo se aprecia un basural de conchas y restos orgánicos.

A. Continuación de la anterior, en dirección oeste. Se halla uno de los sectores más destacados del establecimiento. Consiste en una edificación central con dos plataformas sobre las cuales se asientan tres grandes recintos, uno al centro y dos laterales, de unos 30 por $50 \mathrm{~m}$, asociados a una plaza circular hundida, ubicada al norte, de $25 \mathrm{~m}$ de diámetro por 2,5 $\mathrm{m}$ de profundidad. El recinto central muestra dos niveles y una especie de atrio y vestíbulo con acceso.

Al Este del complejo descrito, excavadores clandestinos han dejado al descubierto paredes y plataformas, hechas de canto rodado con una gruesa capa de argamasa arcillosa con mordiente vegetal. También, al oeste del edificio hay otras unidades arquitectónicas que no se ven desde la superficie. Asimismo, a unos $80 \mathrm{~m}$ se observan otras dos terrazas, de 10 por $4 \mathrm{~m}$ y de 6 por $5 \mathrm{~m}$.

B. Complejo arquitectónico construido sobre el espolón, al Este de la hondonada y en evidente relación con el complejo allí construido. Las estructuras siguen un eje norte-sur por la cumbre y faldas del espolón. La cima, angosta, presenta una secuencia de terrazas y recintos hasta un promontorio redondo del cual se desciende a otra terraza. De aquí al oeste se ubica otra secuencia de terrazas, con frontis al norte, de planta semicircular, que desciende a otra terraza, donde se han hecho excavaciones clandestinas.

En la falda oeste, que mira a la hondonada, se encuentra, a diferentes niveles, una estructura central y dos laterales. La central presenta una secuencia de plataformas con escalinatas de acceso al vestíbulo y al atrio, muy parecidas a las del sector $\mathrm{A}$. En la base termina en un anden, que bordea la estructura.

La falda Este presenta una serie de terrazas angostas con recintos no bien definidos.

En la parte más baja hay un tumbas saqueadas de períodos tardíos, pero debajo de ellas se observan algunas paredes y restos vinculados al Arcaico. Es posible que las viviendas de la mayoría de los habitantes de Piedra Parada haya estado en este sector, por debajo del cementerio tardío, en la parte inferior del establecimiento.

\section{Conservación}

Construcción de canales y excavaciones clandestinas han destruido partes del edificio $\mathrm{A}$. 
El Molno (10 J 02, coordenadas 209000 E Y $8801500 \mathrm{~N}$ )

Establecimiento en la margen derecha del valle. Es uno de los pocos que fue edificado en el fondo del valle. Lo componen cuatro montículos, muy alterados en su forma original por ocupaciones posteriores, particularmente la moderna (Fig. 5).

Al noreste se observan grandes espacios donde se han construido estanques, posiblemente sobre el asiento de antiguas plazas hundidas.

\section{Conservación}

Los montículos arqueológicos están muy destruidos, recortados, aplanados, excavados y transformados. Sobre este asiento se hicieron viviendas o estanques.

LimÁ (10 K-01, COORdenadas 218500 E 8 $799500 \mathrm{~N}$ )

Ubicado en la margen derecha, por encima del valle (Fig. 6).

Estructura circular inscrita, una serie de terrazas con recintos y restos de otros componentes no identificados. Se observan "conchalesn dispersos en la pampa.

A partir de este sitio el valle se estrecha, dando inicio al valle medio inferior.

En el límite con Huaralica hay una estructura de piedras cortadas, muy deteriorada

\section{Era de Pando (11 l3, coordenadas 217000} E r $8801000 \mathrm{~N}$ )

Establecimiento grande, en la margen derecha del río Supe, en el inicio del valle medio inferior, sobre terraza aluvial y estribaciones andinas. En las inmediaciones se encuentra un gran manantial, del cual se extrae agua para alimentar a un antiguo canal de irrigación. Presenta varios componentes de épocas diferentes (Fig. 15).

Contiene arquitectura de diferente diseño, forma y tamaño. Se puede diferenciar pirámides, una de ellas está asociada a una plaza circular hundida, plataformas, estructuras menores y conjuntos habitacionales de diferentes rangos, entre otras.
Destaca una pirámide de planta cuadrangular, de unos 80 por $80 \mathrm{~m}$, asociada a una plaza circular, de $20 \mathrm{~m}$ de diámetro, inscrita en una plataforma. En la cima de la pirámide se aprecia el atrio en el centro, seguido por una plataforma más elevada y dos recintos laterales, al Este y oeste, respectivamente. En el frente sur se desciende del atrio a una plataforma más baja.

Se registró una serie de montículos al oeste, sur y norte de la pirámide principal, compuestos de recintos sobre plataformas con atrio o patio central hundido; así como áreas con recintos habitacionales y otras estructuras, asociadas con las pirámides, formando varios conjuntos. Hay sucesivas terrazas con recintos. El acceso se efectuaba por medio de escaleras.

\section{Conservación}

Afectado por la extracción de piedras con maquinaria. Se encuentra ante una inminente lotización. Los varios sectores de la ciudad muestran piedras pintadas, usadas como hitos en la delimitación de los lotes distribuidos, a la espera de la obra de irrigación.

\section{Pando ( 11 L-02, coordenadas 218500 E $r$} $799500 \mathrm{~N}$ )

Establecimiento de la margen derecha, con varios componentes de períodos tardíos. El perteneciente al período Arcaico consiste en una estructura con secuencia de plataformas, asociada a una plaza circular hundida. Una serie de terrazas con recintos, probablemente de conjuntos habitacionales se encuentran en las inmediaciones y podrían corresponder a viviendas de este período (Fig. 7).

\section{Conservación}

Muy afectada por la construcción de una vivienda sobre la pirámide y por el acondicionamiento de terrazas de cultivo.

\section{LURIHUASI (11M-07, COORDENADAS $221500 \mathrm{v}$ E $8796500 \mathrm{~N}$ )}

Establecimiento en la margen izquierda.

Numerosos componentes arquitectónicos: pirámides, plataformas, conjuntos residenciales, terrazas, etc. distribuidos en un ordenamiento casi circular, en relación con los bordes del cono de deyec- 
ción, por encima del valle. La arquitectura monumental presenta diversos tipos morfológicos, en variados tamańos (Fig. 16).

\section{Conservación}

Ha sido afectado por el saqueo del cementerio tardío, que se encuentra en la entrada del sitio

\section{Miraya (11 M-06, coordenadas 223500 E r 8796000 N)}

Establecimiento de la margen izquierda, sobre la terraza y cono de deyección (Fig. 17).

Conjunto aglutinado de montículos piramidales de diferente tamaño y forma. Hay pirámides, plataformas en secuencia, plataformas, plazas circulares, etc.

Ocupaciones desde el Arcaico Tardío.

\section{Conservación}

Muy afectado por la expansión de las tierras de cultivo del actual poblador; así como por los cabreros que, periódicamente lo ocupan con sus animales $y$ corrales.

Chupacigarro (12M-01, coordenadas 223 500 E r 8795500 N)

Ubicado en la margen izquierda sobre una terraza, en el cono de deyección, en los espolones y faldas de cerros (Fig. 8).

Conjunto de estructuras arquitectónicas, presidido por un edificio con una secuencia de plataformas y una plaza circular hundida. Se han ubicado varios geoglifos.

\section{Conservación}

La expansión agricola ha destruido totalmente la parte baja del establecimiento. Sólo permanecen las construcciones que estuvieron en las partes elevadas.

\section{Caral (12N-02, coordenadas 225000 E y 8 $795500 \mathrm{~N}$ )}

Ubicado en la margen izquierda, sobre una terraza aluvial (Fig. 19).
Conjunto de estructuras arquitectónicas distribuidas en dos sectores, las más grandes y voluminosas en el sector alto; las más bajas y pequeñas en el sector bajo. La ciudad se caracteriza por la diversidad de construcciones de carácter público como privado. Destacan dos plazas circulares hundidas.

\section{Pueblo Nuevo (11 M-03, coordenadas 222 O00 E r 8798000 N)}

Establecimiento grande, ubicado en la margen derecha. Forma parte del conjunto de establecimientos que están en directa asociación con Caral.

Se ubica frente a Lurihuasi, en el cono de deyección de una antigua quebrada seca y sobre las estribaciones. Consiste en un conjunto aglomerado de por lo menos 10 estructuras piramidales principales con otras anexas. Los montículos muestran una secuencia de plataformas con una serie de recintos. Es el establecimiento del valle con mayor trabajo constructivo (Fig. 18).

Al fondo de la quebrada destacan dos estructuras, una muy alta con plataformas escalonadas, asociadas a una plaza circular hundida, casi cubierta por la remodelación de las plataformas y otra plaza circular adosada a una pirámide con plataformas acondicionadas a una elevación natural. Una serie de terrazas con recintos se hallan entre los montículos.

Todas las estructuras tiene sus fachadas hacia el espacio donde se encuentran las plazas.

\section{Conservación}

Los montículos ubicados más cerca del valle están ocupados por las viviendas de criadores de cabras, quienes han construido una serie de corrales. Por tratarse de una población en principio migrante, está propiciando el traslado de otros criadores y el poblado va creciendo en detrimento del establecimiento arqueológico.

\section{Cerro Colorado (11 M-01, coordenadas 223 500 E r 8'797 000 N)}

Ubicado en la margen izquierda, en la parte baja de un cono de deyección y en parte alta de las estribaciones andinas (Fig. 9). 
Consiste en dos conjuntos, cada uno con una serie de terrazas con recintos y presidido por una plaza circular hundida.

El conjunto de la parte baja está muy deteriorado por las ocupaciones más tardías.

\section{Allpacoto (coordenadas 225500 E y 8 ' 796 $500 \mathrm{~N}$ )}

Establecimiento con componentes de diversos períodos. El correspondiente al Arcaico fue construido en la quebrada de ese mismo nombre, en la margen derecha del río Supe (Fig. 10).

Está frente a Caral, en el valle medio inferior, en una zona provisra de puquiales y en las cercanías a vias naturales de comunicación con el valle de Pativilca y la sierra de Cajatambo.

Muestra dos sectores de construcciones, con diseños de asentamiento y formas arquitectónicas diferenciados, además de estar separados espacialmente. Ellas podrían corresponder a dos períodos de tiempo distintos:

Sector A. Conjunto de pirámides, dispuestas alrededor de un espacio abierto. Al noroeste de este núcleo de estructuras públicas se observa otro conjunto de monrículos menores.

Sector B. Al noreste del anterior, en el borde de la terraza se haya un edificio con plaza circular hundida, muy destruidos por maquinaria. Una serie de terrazas al Este y oeste podrían corresponder a conjuntos habitacionales.

\section{Conservación}

El establecimiento ha sido intervenido con fines agrícolas y otros. El más afectado es el sector $\mathrm{B}$, donde sólo queda una parte ínfima de la terraza y de la plaza circular. El sector $\mathrm{A}$ también está en peligro, pues el espacio interno, alrededor del cual están las pirámides viene siendo cultivado y se aprovecha el agua del puquio que allí se encuentra (Haas, com. pers.).

\section{Peñico (13C-02, coordenadas 234500 E y 8} $791000 \mathrm{~N}$ )

Ubicado en la margen izquierda, en el valle medio superior, sobre un espolón, paralelo al río y un gran cono de deyección. Se encuentra en una vía de tránsito que une los valles de Huaura, Supe y el alto Supe (Fig. 20).

Tiene dos sectores, uno alto, sobre el espolón, con estructuras de diversos períodos. Destaca una secuencia de pirámides y terrazas. Asociadas a una plaza circular hundida. En la falda sur se encuentra una secuencia de plataformas, asociadas a plazas circulares. En el sector bajo, hay diversas construcciones, entre las que se destaca un edificio con secuencia de plataformas, asociado a una plaza circular.

\section{Conservación}

Estructuras deterioradas por las ocupaciones sucesivas del espolón. Inclusive se construyó allí la antigua casa hacienda.

\section{Huacache (12C-01, coordenadas $234500 \mathrm{E}$ Y $8792000 \mathrm{~N}$ )}

Ubicado en la margen derecha y en la parte media superior del valle, sobre el espolón que corre paralelo al río Supe, frente a Peñico y en uno de los lados de la quebrada que conecta esta parte del valle con el sector de Las Minas (Fig. II).

Conjunto de estructuras sobre terrazas, adecuadas a la configuración del terreno, asociadas a plazas circulares hundidas $\mathrm{y}$ a una serie de recinros.

\section{Cerro Blanco (12D-07, coordenadas 223 500 E r 8797500 N)}

Ubicado en la margen izquierda, en la parte media superior del valle. Alejado, al fondo de una terraza, muy cerca de la cadena andina, desraca una estructura arquitectónica con una secuencia de plataformas sin plaza circular. Se pudo notar un atrio, antesala y plaza cuadrangular en la parte baja y las estructuras correspondientes a la pirámide y recintos posteriores en la parte alra (Fig. 12). 
CAPILla $(12 E-04,240300$ E y 8794000 N)

Ubicado en la margen izquierda, en la parte media superior del valle, en un pequeño cono de deyección, sobre una terraza. Destaca una pequeña estructura arquitectónica de planta cuadrangular con pequeńos ingresos laterales. Aparentemente se trata de un atrio de 10 metros de lado por $3 \mathrm{~m}$ de alto (Fig. 13).

\section{JaIva (12E-01, 241000 E y 8795000 N)}

En la margen izquierda, sobre un espolón, en la parte media superior del valle (Fig. 14).

Secuencia de plataformas, adaptadas a la configuración del terreno. Destacan dos plazas circulares hundidas unidas por una larga escalinata que sube por la ladera; en la parte más alta se distingue un conjunto de recintos, además de las terrazas y otros recintos en las laderas.

\section{APÉNDICE 2}

\section{PROCEDIMIENTOS DE MEDICIÓN}

\section{A. Extensión de los ESTABleciMientos EN HECTA- REAS:}

Se ha efectuado el cálculo espacial del tamaño de los establecimientos desde la percepción de superficie pues, aparte de Caral, los otros establecimientos no han sido excavados todavía. Este procedimiento tiene fuertes limitaciones, primero porque pueden haber estructuras debajo de la tierra que no son percibidas desde la superficie $y$, segundo, porque puede tratarse de un lugar extenso pero tener estructuras de bajo volumen de trabajo, caso Era de Pando en comparación con Pueblo Nuevo. Hemos tratado de subsanar esta última haciendo también los cálculos de volumen. Pero estamos conscientes que sólo las excavaciones futuras permitirán mayores precisiones.

Para calcular el espacio ocupado por cada establecimiento se tomaron las medidas en los planos a escala de 1:2000; se formaron polígonos cerrados que contuvieran a todos los edificios registrados en el interior de cada establecimiento. Se usaron algunos elementos topográficos como límites, fuertes desniveles, terrazas geológicas, laderas, etc. Se procuró ubicar al establecimiento no sólo en su dimensión cultural sino también geográfica.

\section{B. VOLUMEN E INVERSIÓN DE FUERZA de TRABajo}

Para confrontar los resultados obtenidos por el cálculo espacial, hemos considerado, asimismo, la variable fuerza de trabajo invertida, mediante el cálculo hecho sobre la base de las construcciones arquitectónicas. Debemos advertir, asimismo, que en tanto no se hagan excavaciones, éstas son aproximaciones para conocer la diversidad de establecimientos identificada en el valle de Supe. Una variable que no podemos controlar por ahora es la antigüedad de los establecimientos, pues el tiempo de ocupación de ellos también podría estar en relación con el mayor o menor volumen de la arquitectura.

Se hizo la operación en base a las dimensiones, a escala, de cada estructura (largo por ancho), y se multiplicó el resultado por la altura aproximada de cada edificio. Esta última medida fue calculada en el campo a simple vista. Si bien no es exacto el volumen resultante en metros cúbicos de cada estructura, aún con el error estándar que se espera, este procedimiento permite apreciar la relación porcentual de fuerza de trabajo invertida en cada tipo de edificio y establecimiento. Se puede disponer, así, de otros indicadores para inferir la relación jerárquica entre los centros urbanos del valle.

\section{Tipologia de Estructuras:}

La definición de cada tipo de estructura está referida básicamente al aspecto morfológico general: la forma de la planta del edificio (en relación con figuras geométricas: cuadrangular, rectangular y circulat), el volumen (pirámides y plataformas) o la combinación de estos elementos. 